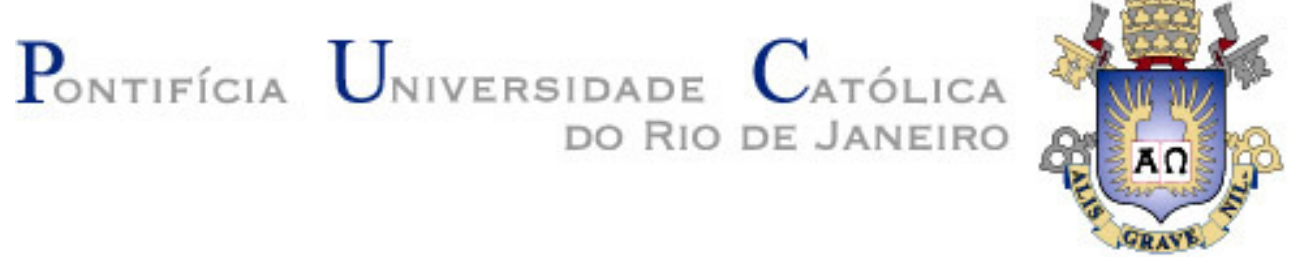

Roberto Valle Braga

\title{
Aquisição de Chip de Telefonia Pré-paga por \\ Consumidores de Baixa Renda: Relevância do ponto de venda na relação de troca
}

Dissertação de Mestrado

Dissertação apresentada ao Programa de Pósgraduação em Administração de Empresas da PUCRio como requisito parcial para obtenção do grau de Mestre em Administração de Empresas

Orientador: Prof. Marcus Wilcox Hemais

Rio de Janeiro

Abril de 2018 


\title{
Pontifícia $U_{\text {Niversidade }}$ C atólica $_{\text {a }}$

Roberto Valle Braga

\begin{abstract}
Aquisição de chips de telefonia pré-paga por consumidores de baixa renda: relevância do ponto de venda na relação de troca
\end{abstract}

Dissertação apresentada como requisito parcial para obtenção do grau de Mestre pelo Programa de PósGraduação em Administração de Empresas da PUCRio. Aprovada pela Comissão Examinadora abaixo assinada.

Prof. Marcus Wilcox Hemais

Orientador

Departamento de Administração - PUC-Rio

Prof. Luis Alexandre Grubits de Paula Pessôa

Departamento de Administração - PUC-Rio

Prof. João Felipe Rammelt Sauerbronn

UNIGRANRIO

Prof. Augusto Cesar Pinheiro da Silva

Vice-Decano de Pós-Graduação do CCS - PUC-Rio

Rio de Janeiro, 25 de abril de 2018 
Todos os direitos reservados. É proibida a reprodução total ou parcial do trabalho sem autorização da universidade, do autor e do orientador.

\section{Roberto Valle Braga}

Graduou-se em Marketing pela faculdade Unesa-RJ em dezembro de 2010. Pós-graduado com MBA executivo pelo Instituto Coppead de Administração em dezembro de 2014. Trabalhou em empresas como Amber e Telefônica Vivo.

Ficha Catalográfica

Braga, Roberto Valle

Aquisição de chip de telefonia pré-paga por consumidores de baixa renda : relevância do ponto de venda na relação de troca / Roberto Valle Braga ; orientador: Marcus Wilcox Hemais. - 2018.

57 f. : il. ; $30 \mathrm{~cm}$

Dissertação (mestrado)-Pontifícia Universidade Católica do Rio de Janeiro, Departamento de Administração, 2018.

Inclui bibliografia

1. Administração - Teses. 2. Telefonia celular. 3. Chip. 4. Pré-pago. 5. Consumidor de baixa renda. 6. Banca de jornal. I. Hemais, Marcus Wilcox. II. Pontifícia Universidade Católica do Rio de Janeiro. Departamento de Administração. III. Título. 
Para meus pais, irmão e well, pela motivação, apoio e companheirismo. 


\section{Agradecimentos}

A Deus que guia todos os dias meus passos e me permitiu estar aqui.

A meus pais que me incentivaram e apoiaram em todos os momentos difíceis de minha vida.

Ao meu orientador Marcus Hemais pela paciência e dedicação.

Ao Prof. Luís Alexandre pessôa pelo apoio.

A meus amigos que estiveram ao meu lado na trajetória do mestrado.

A minha madrinha e mãe que sempre distante me apoiou.

Aos meus colegas da PUC-RIO que proporcionaram momentos de muita descontração e apoio.

Ao meu irmão pela parceria de sempre.

A Bel por toda a parceria, dedicação e amor. 


\section{Resumo}

Braga, Roberto Valle; Hemais, Marcus Wilcox. Aquisição de chips de telefonia pré-paga por consumidores de baixa renda: Relevância do ponto de venda na relação de troca. Rio de Janeiro, 2018. 57p. Dissertação de Mestrado - Departamento de Administração, Pontifícia Universidade Católica do Rio de Janeiro.

O setor de telecomunicações no Brasil apresentou elevados índices de crescimento nos últimos anos, o que pode ser atribuído, em parte, pela criação dos planos de telefonia móvel pré-pago, uma modalidade de serviço de telecomunicação que possibilitou o ingresso das classes de baixa renda nesse mercado, alcançando a marca de 160 milhões de linhas pré-pago. O sucesso comercial do segmento pré-pago com consumidores de baixa renda ajudou a contribuir com as vendas do canal de pequeno varejo, que incluem bancas de jornal, farmácias, padarias, papelarias, armarinhos, entre outros. As bancas de jornal destacam-se nas vendas, em especial no município do Rio de Janeiro, por representarem um volume considerável do total de vendas do segmento pré-pago na região. Apesar de ser um importante canal de vendas para operadoras telefônicas, poucos estudos em marketing se dedicam a pesquisar melhor bancas de jornal como pontos de vendas para consumidores de baixa renda. $\mathrm{O}$ presente estudo, portanto, analisa os significados associados por classes menos favorecidas a bancas de jornal no município do Rio de Janeiro para a compra de chips prépago. Para isso, foram feitas entrevistas em profundidade com consumidores de baixa renda que utilizavam bancas de jornal para comprar chips pré-pagos de celular. A partir dos dados coletados, foi possível entender como esses indivíduos se relacionam com bancas, a importância do jornaleiro nessa relação e os motivos que os levam a consumir produtos telefônicos nesse ponto de vendas.

\section{Palavras-chave}

Telefonia celular; chip; pré-pago; consumidor de baixa renda; banca de jornal. 


\section{Abstract}

Braga, Roberto Valle; Hemais, Marcus Wilcox (Advisor). Acquisition of prepaid phone chips by low-income consumers: Relevance of the point of sale in the exchange ratio. Rio de Janeiro, 2018. 57p. Dissertação de Mestrado - Departamento de Administração, Pontifícia Universidade Católica do Rio de Janeiro.

The telecommunications sector in Brazil has shown high growth rates in recent years, which can be attributed in part to the creation of prepaid mobile telephony plans, a modality of telecommunication service that allowed the entry of low-income classes in this market, reaching the mark of 160 million prepaid lines. The commercial success of the prepaid segment with low-income consumers has helped to contribute to small retail sales, which include newsstands, pharmacies, bakeries, stationery, among others. Newsstands stand out in sales, especially in the city of Rio de Janeiro, since they represent a considerable volume of total sales of the prepaid segment in the region. Despite being an important sales channel for telephone operators, few marketing studies are dedicated to better researching newsstands as sales points for low-income consumers. The present study, therefore, analyzes the meanings associated by less favored classes to newsstands in the city of Rio de Janeiro for the purchase of prepaid chips. To do this, in-depth interviews were conducted with low-income consumers who used newsstands to buy prepaid cellphone chips. From the data collected, it was possible to understand how these individuals relate to newsstands, the importance of the journeyman in this relationship and the reasons that lead them to consume telephone products at this point of sale.

\section{Keywords}

Mobile telephony; chip; prepaid; low-income consumer; newsstand. 


\section{Sumário}

1. Introdução 11

$\begin{array}{ll}1.1 \text { Motivação } & 13\end{array}$

$\begin{array}{ll}\text { 1.2. Objetivo } & 14\end{array}$

1.3. Delimitação do Estudo 14

1.4. Relevância do Estudo 15

2. Referencial Teórico 16

2.1. Características do Consumidor de Baixa Renda 16

2.2. Adequação do Ponto de Venda para Atender o Consumidor De Baixa Renda 18

2.3. Relevância do Consumo de Serviços de Telefonia Móvel para o Consumidor de Baixa Renda $\quad 20$

3. Metodologia 23

3.1. Tipos de Pesquisa 23

3.2. Seleção dos Entrevistados $\quad 24$

3.3. Procedimento de Coleta de Dados 25

3.4. Procedimento de Análise de Dados 28

3.5. Limitações do Método 29

4. Análise dos Dados $\quad 30$

4.1. Localização e Conveniência das Bancas de Jornal 30

4.2. Relação Interpessoal e Confiança no Ponto de Venda 31

4.3. Flexibilidade de Crédito Disponibilizada pelo Ponto de Venda 33

4.4. Estratégia de Comunicação do Ponto de Venda 34

5. Conclusão, Recomendações Gerenciais e Sugestões de Estudos Futuros $\quad 35$

5.1. Recomendações Gerenciais 37

5.2. Sugestões de Estudos Futuros 38

6. Referências Bibliográficas $\quad 39$

Anexo I $\quad 43$

Anexo II $\quad 44$

Anexo III $\quad 45$

Anexo IV $\quad 47$ 


\section{Lista de figuras}

Figura 1: A riqueza na base da pirâmide 


\section{Lista de tabelas}

Tabela 1: Perfil resumido dos entrevistados

28

Tabela 2: Modelo percepção de valor no varejo aplicado em bancas. 


\section{Introdução}

O setor de telecomunicações no Brasil vem sofrendo constantes mudanças e crescendo desde o término do monopólio estatal de telecomunicações em 1994 e a sua subsequente privatização em 1998. Segundo dados do Anuário 2016 (FÓRUM EDITORIAL, 2016), em 2015 o mercado de telecomunicações brasileiro registrou uma receita liquida de 167,5 bilhões de reais, sendo 30,9\% da receita líquida total do setor oriunda da telefonia móvel (51,8 bilhões de reais). De acordo com a Agência Nacional de Telecomunicações (Anatel), em junho de 2017 o serviço de telefonia móvel no Brasil alcançou a marca de 242,1 milhões de linhas, sendo $66,16 \%$ desse total proveniente de linhas do segmento pré-pago (160,1 milhões). Esse tipo de serviço de telecomunicação consiste em o consumidor pagar pelo serviço na forma de crédito antecipadamente à prestação do serviço, em lugar de assumir uma assinatura básica com o pagamento após a prestação do serviço.

Apesar de somente terem sido disponibilizadas ao consumidor em 1998 (TELECO, 2003), as linhas móveis pré-pagas já apresentam grande relevância para o mercado de telecomunicações. A consultoria Teleco (BRUNO, 2016) estima que a receita advinda do segmento pré-pago representa entre $40 \%$ e $60 \%$ das receitas de serviços das operadoras e possuem um gasto médio de $\mathrm{R} \$ 15$ a $\mathrm{R} \$$ 20 (ROSA, 2014), com a vantagem adicional de que, por serem pagas antes do consumo, não apresentam risco de inadimplência do consumidor. O mercado de pré-pago também é movimentado pela venda de recarga dos créditos, com $80 \%{ }^{1}$ do volume total de recargas sendo oriundo de canais de distribuição massivos, que são aqueles que garantem capilaridade e volume de vendas, tais como os pontos de vendas de pequeno varejo (como, por exemplo, bancas de jornal, padarias, postos e gasolina, bares e etc.) (ROSA, 2014). A representatividade deste canal

\footnotetext{
${ }^{1}$ Dados obtidos junto a empresa Telefônica S.A / Vivo, referente a participação de vendas de chips pré-pago nos canais de pequeno varejo no município do Rio de janeiro em setembro de 2017.
} 
para o segmento pré-pago é ainda maior quando se fala em volume de ativações ${ }^{2}$ : $97,8 \%$ das linhas são ativadas no canal massivo ${ }^{3}$.

Dentre os diferentes tipos de pequeno varejo relevantes para o segmento pré-pago de telefonia móvel, a banca de jornal tem destaque, com representatividade de $32 \%$ na venda de chips pré-pagos, no município do Rio de Janeiro ${ }^{4}$. Conceitualmente, a banca de jornal é "um espaço que é cedido e regulado pelo poder público, sendo que seu usufruto sucede por comerciantes individuais. Esta atividade é licenciada e fiscalizada pela prefeitura e deve seguir uma legislação específica" (SILVA, FIQUEIREDO, SANTOS, 2014, p. 85). As bancas de jornal começaram a operar no ano de 1860 no Brasil e, no Rio de Janeiro, em 1910. Com o tempo, passaram a ter um papel de referência nos bairros em que se encontram e apresentam uma relação de proximidade com o público local. Segundo Soares (2014), “as bancas de jornal são muito mais do que locais de venda de impresso. A convivência entre proprietários e clientes, com o tempo, vai construindo uma relação de afeição entre as pessoas".

Apesar de terem se transformado em referências, tais bancas vêm passando por um processo de transformação, uma vez que os meios de comunicação e informação físicos se encontram em processo de digitalização. Consequentemente, tais canais estão se tornando locais mais similares a lojas de conveniência, com a oferta de diversos outros tipos de produtos, que não somente jornais ou revistas. A recarga de linhas pré-paga, por exemplo, já é uma das principais fontes de receita para os mesmos (NOGUEIRA, 2017).

Em geral, os maiores consumidores de serviços pré-pagos de telecomunicações são consumidores de baixa renda. Segundo pesquisa do Instituto Data Popular (SIMON, 2013), 81\% dos consumidores da classe C que possuíam linha de telefonia móvel em 2013 estavam vinculados ao serviço prépago. Considerando que o orçamento desse consumidor é limitado, o advento desse serviço, que permite realizar o pagamento antecipado ao uso em um sistema de créditos para consumo sem franquia mínima mensal ou aprovação de crédito, garantiu a esse público a possibilidade de aderir ao serviço. Bacha (2009) indica

\footnotetext{
${ }^{2}$ Ativação é quando o cliente realiza a utilização de uma nova linha pela primeira vez.

${ }^{3}$ Dados obtidos junto a empresa Telefônica S.A / Vivo, referente a participação de vendas de chips pré-pago nos canais de pequeno varejo no município do Rio de janeiro em setembro de 2017.

${ }^{4}$ Dados obtidos junto a empresa Telefônica S.A / Vivo, referente a participação de vendas de chips pré-pago nos canais de pequeno varejo no município do Rio de janeiro em setembro de 2017.
} 
alguns valores sociais percebidos pelo público de baixa renda ao utilizar os serviços de telecomunicações, tais como socialização, comunicação e desenvolvimento pessoal. Por existir uma demanda de consumidores de baixa renda a tais serviços de telecomunicações, é importante para empresas desse setor adaptarem seus serviços para terem apelo ao público de baixa renda e, assim, obter sucesso em vendas a ele (PRAHALAD, 2005).

Além de grandes usuários dos serviços pré-pagos, consumidores de baixa renda são mais propensos a adquirirem seus créditos telefônicos em pontos de venda do pequeno varejo, tais como bancas de jornais, do que em lojas de operadoras de telecomunicações (BARBOSA, 2009). Segundo Parente et al. (2008), há uma relação de confiança e reciprocidade entre o consumidor de baixa renda e o ponto de venda de pequeno varejo, pois esses consumidores se sentem desconfiados de grandes empresas, dado o distanciamento que existe entre as partes, e, por isso, preferem comprar seus produtos em locais conhecidos por eles.

Embora existam autores brasileiros que discutam a relação de consumidores de baixa renda com os serviços de telecomunicações, tais como Barbosa (2009) e Bacha (2008), são escassos os que analisam como o ponto de vendas influência em sua decisão por adquirir esses serviços de uma ou de outra operadora, especialmente quando o foco é o pequeno varejo - mais especificamente, bancas de jornal, que geralmente atuam como lojas multimarcas, oferecendo produtos de diversas operadoras.

\section{1. Motivação}

O setor de telecomunicações vem ganhando grande importância no dia a dia da sociedade, uma vez que a comunicação via dispositivos eletrônicos a cada dia é mais imprescindível para os indivíduos. Os inúmeros relatos e evidências de que o acesso às telecomunicações por camadas menos favorecidas da sociedade gera maior desenvolvimento e proporciona progresso aos mesmos, reforçam a importância do setor na sociedade. Essa relevância gera a necessidade de uma melhor compreensão sobre como as relações de trocas de seus produtos se dão no ambiente de compra. 
Apoiado na crença de que existem muitas oportunidades de melhoria nas relações do setor de telecomunicações com o cliente e consequente captura de receitas incrementais, considerando-se a carência de uma melhor compreensão dos hábitos e anseios das camadas de baixa renda no setor de telecomunicações, em especial na telefonia móvel pré-paga, o ora pesquisador buscou aprofundar-se no tema.

\section{2. \\ Objetivo}

Em razão desse contexto, o presente estudo tem como objetivo analisar o que leva consumidores de baixa renda a utilizarem bancas de jornal como um local de aquisição de produtos pré-pagos de telefonia móvel.

\section{3. \\ Delimitação do estudo}

O Brasil é um país que possui mais celulares do que habitantes. Segundo dados do TELECO, em agosto de 2017 o país apresentava uma densidade de 116,53 linhas de celular por cada 100 habitantes. Dados da Agência Nacional de Telecomunicações (Anatel), em junho de 2017, demonstram que 66,16\% dessas linhas se encontravam no segmento pré-pago, evidenciando a predominância desse no setor. Em razão dessa importância, o foco do estudo se dará somente no consumo relacionado aos serviços pré-pagos de telecomunicações.

Um dos principais canais de vendas de serviço pré-pago é o pequeno varejo, que representa $97,8 \%$ das vendas de chip e, por isso, foi escolhido como objeto de estudo da pesquisa ${ }^{5}$. Contudo, o canal de vendas do pequeno varejo apresenta grande variação de perfil, já que engloba bancas de jornal/revistarias, farmácias/drogarias, açougues, mercearias, dentre outros. Para garantir um resultado consistente e reduzir os vieses decorrentes dessa variação, optou-se por concentrar a pesquisa no segmento de bancas de jornal, tipo de pequeno varejo que detém a maior participação no volume de vendas de chips pré-pago do município do Rio de Janeiro, com $32 \%^{2}$.

\footnotetext{
${ }^{5}$ Dados obtidos junto a empresa Telefônica S.A / Vivo, referente à participação de vendas de chips pré-pago nos canais de pequeno varejo no município do Rio de janeiro em setembro de 2017.
} 
Sendo o Brasil um país de dimensões continentais e que possui grande diferença cultural entre suas regiões, faz-se necessário delimitar uma área geográfica menor que viabilize a realização da pesquisa. Para tanto, optou-se pela cidade do Rio de Janeiro, que representa $22,4 \%$ do total de vendas de chip no Estado do Rio de Janeiro e 1,7\% do Brasil ${ }^{2}$.

\section{4 .}

\section{Relevância do estudo}

O presente estudo apresenta relevância tanto para o meio empresarial, quanto para o meio acadêmico. Para o meio empresarial, é importante entender mais sobre a relação entre consumidores de baixa renda e bancas de jornais dada a relevância desse público e do ponto de vendas para os negócios das operadoras de telecomunicações. Considerando que o mercado de telecomunicações no Brasil é de alta concorrência, com pequenas margens de vendas, faz-se importante maior conhecimento sobre o fenômeno em questão a fim de adequar estratégias de marketing que possam criar diferenciais às operadoras.

Para o meio acadêmico, ainda são poucos os estudos que buscam entender mais a fundo o comportamento de consumidores de baixa renda e sua relação com o ponto de vendas (PARENTE et al., 2008), especialmente quando o varejista em questão são bancas de jornais. 


\section{2 \\ Referencial teórico}

Nesse capítulo serão apresentados os principais temas que darão suporte à pesquisa, a saber: características do consumidor de baixa renda, a importância da adequação do ponto de venda para atender ao consumidor de baixa renda e a relevância do consumo de serviços de telefonia móvel para o consumidor de baixa renda.

\section{1.}

\section{Características do consumidor de baixa renda}

Prahalad (2005) aborda a riqueza que existe na base da pirâmide ao mostrar o poder de compra das classes sociais menos abastadas. Conforme ilustra a Figura 1, o autor indica que existem mais de quatro bilhões de pessoas que vivem com até dois dólares por dia. É um grande mercado em potencial ainda inexplorado pelas corporações. Contudo, ao tornar produtos e serviços acessíveis às classes mais baixas, as empresas conseguem maiores lucros e injetam dinheiro na economia, o que, no final, beneficia toda a sociedade (PRAHALAD, 2005).

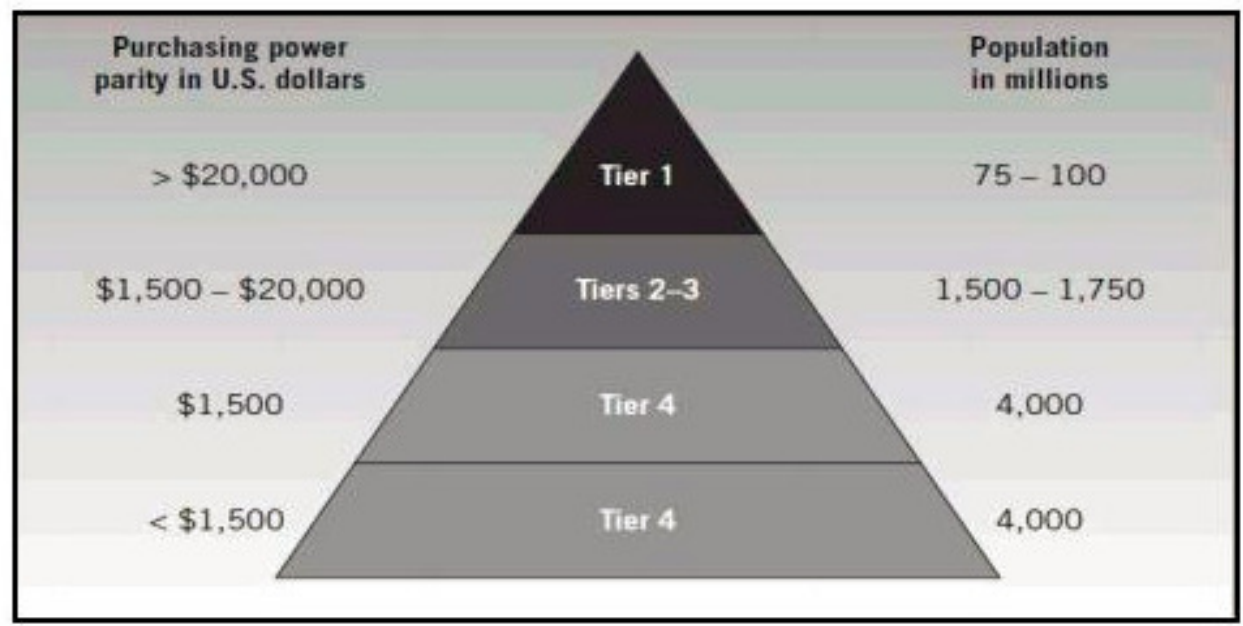

Figura 1: A riqueza na base da pirâmide Fonte: PRAHALAD, C. K. Porto Alegre: Artmed, 2005. Pagina 4. 
O público de baixa renda era comumente ignorado pelas empresas, que entendiam que este nicho não possuía potencial de consumo. Dessa forma, não investiam em adaptações de produtos e serviços que pudessem atender as necessidades desta classe. (PRAHALAD, 2005). De fato, a questão do poder de compra deve ser analisada de forma diferenciada, já que por ter poucos recursos, este é um público que decide o que comprar de acordo com o dinheiro que tem disponível naquele momento, e opta por produtos que oferecem qualidade e estão adequados ao seu perfil de consumo (PRAHALAD, 2005).

Apesar de possuir uma renda limitada, Kunreuzher (1973) indica que o consumidor de baixa renda costuma pagar mais caro pelos produtos, uma vez que, por questões de restrição orçamentária, fraciona suas compras mensais e opta por embalagens menores, que geralmente possuem um preço mais elevado proporcionalmente às embalagens maiores. Outro fator que torna mais dispendiosa a aquisição de produtos pelo segmento de baixa renda é a dificuldade de acesso aos grandes varejos, fazendo com que efetue suas compras em estabelecimentos de menor porte, que por sua vez possuem preços mais altos.

Alguns estudos exploraram o potencial dessa parcela de mercado e as estratégias empresariais para atuação junto ao público de baixa renda (PRAHALAD, HAMMOND, 2002; PRAHALAD, 2005). As dificuldades de acesso ao grande varejo (ALWIT, DONLEY, 1997; GOLDMAN, 1978), mitos relacionados a este mercado (HAMMOND, PRAHALAD, 2004; ANDERSON, 2002) e o comportamento de compra do consumidor de baixa renda na aquisição de produtos a preços mais elevados (KEMPEN, 2004; KUNREUZHER, 1973) também são temas abordados.

Parente et al. (2008, p. 53) cita que "deve-se reconhecer que os consumidores, de um modo geral, não dão o mesmo valor a diferentes atributos, razão por que uma mesma empresa varejista pode ter muito valor para determinado consumidor e pouco para outro". Os autores também abordam a importância do entendimento do comportamento de compra do consumidor de baixa renda para se obter sucesso no varejo, uma vez que a percepção de valor é subjetiva e varia de acordo com o público e o produto. Segundo Parente et al. (2008), há nove fatores associados diretamente à relação custo/benefício que dimensionam a equação de valor, conforme ilustra a figura a seguir. 


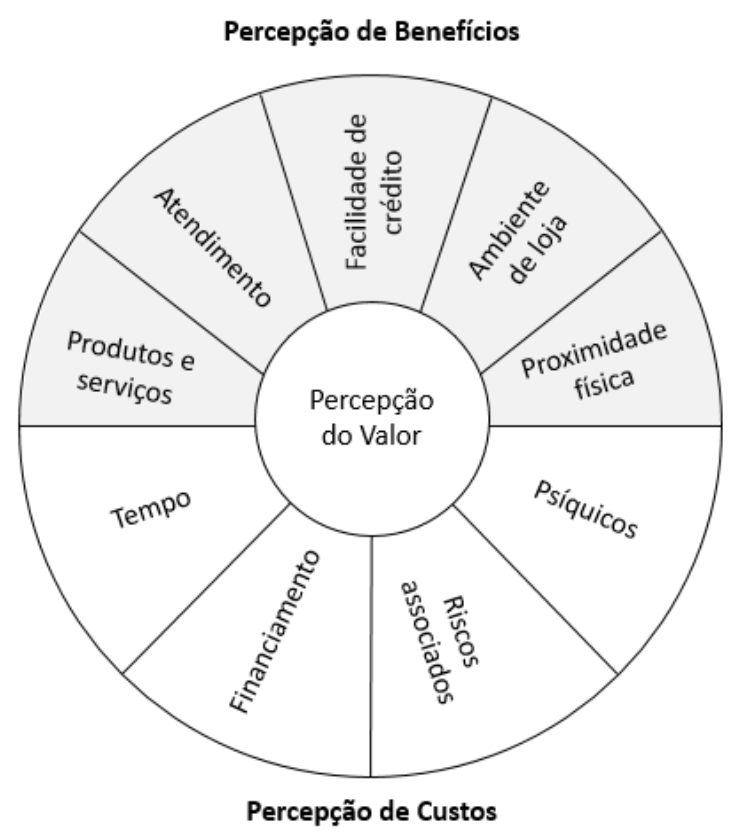

Figura 2: Percepção do valor, benefícios e custos Fonte: PARENTE, LIMEIRA, BARKI, 2008.

Dos cinco atributos relacionados à Percepção de Benefícios, quatro estão relacionados ao ponto de venda: atendimento; facilidade de crédito; ambiente de loja; e proximidade física.

Barki (2005) discute algo similar, quando expõem alguns fatores comportamentais que caracterizam a baixa renda brasileira em análise a partir de pesquisas realizadas pelos institutos Data Popular (2004), Booz Allen Hamilton (2003) e Latin Panel (2004). Destacam-se o conservadorismo acima da média, o gosto pela fartura, a baixa autoestima, a dignidade, a preferência por lojas da vizinhança, a flexibilidade de crédito e o contato pessoal.

\section{2.}

Adequação do ponto de venda para atender o consumidor de baixa renda

Os estudos que abordam o comportamento de compra do consumidor de baixa renda demonstram que o ponto de venda tem relevância e gera valor para esse público. Sendo assim, faz-se necessário analisar o que a literatura de marketing fala sobre este tema. 
Alguns estudos evidenciam as particularidades dos hábitos do consumidor de baixa renda e as adaptações de pontos de vendas em alguns segmentos para atrair mais consumidores desse público. Barki (2005) apresenta a importância de se trabalhar no ponto de venda com um mix de produtos que englobe marcas líderes e marcas de segunda linha. O autor também aborda a importância da adequação da estratégia de comunicação no ponto de venda para o consumidor de baixa renda.

Atentas ao potencial do mercado, grandes redes varejistas iniciaram novas investidas junto aos consumidores de baixa renda, procurando criar modelos voltados para atender às necessidades dessa população, tais como Wal Mart (Wal Mart Todo Dia), Carrefour (Dia\%) e Grupo Pão de Açúcar (CompreBem), segundo Barki (2005). Prahalad (2005) cita casos de empresas que estão alcançando sucessos significativos focando no consumidor de baixa renda, como, por exemplo, as Casas Bahia, que por meio de uma estrutura organizacional e estratégias bem definidas atende adequadamente aos anseios desse segmento.

Por outro lado, segundo Barki (2005), ainda que diversas empresas tenham avançado nesse sentido, nota-se que diversos formatos criados ainda não obtiveram o sucesso esperado. Em parte, isso é devido à dificuldade de conseguirem capilarizar seus modelos na escala necessária para atendimento desse público e porque o segmento de baixa renda ainda prefere comprar no pequeno e médio varejo local devido à empatia estabelecida entre as partes:

"Percebe-se ainda uma incompatibilidade das estratégias adotadas pelas grandes empresas em atuação no mercado de baixa renda. Via de regra, ocorre uma extrapolação das estratégias adotadas em países desenvolvidos para os mercados emergentes, ou então, a atuação no mercado de baixa renda é realizada com base em mitos que não se comprovam na prática." (BARKI, 2005, p.5)

A exemplo disso, segundo Parente et al. (2008), pesquisas indicam que redes de supermercados que valorizam em excesso o fator preço e são especificamente voltados para esse público não estão apresentando sucesso. Para Parente et al. (2008), esses varejistas somente conseguirão ter sucesso com o público de baixa renda quando focarem seus esforços e iniciativas no atendimento das necessidades peculiares desse segmento, em consonância com o que é apresentado por Prahalad (2005), que aborda a importância das empresas buscarem atender esse segmento com uma proposta de valor específica e diferenciada das demais camadas sociais. 
Parente et al. (2008) abordam alguns dos valores que norteiam as ações e o sentimento de pertencimento do público de baixa renda e são críticos de sucesso para a atuação do varejo. São eles os sentimentos de reciprocidade e confiança, comumente encontrados nas ações do dia a dia desse público. A força desses sentimentos em toda a lógica que permeia as relações sociais desse grupo é relevante e fica evidente no sucesso de varejos de pequeno porte com esse público. Porém, proximidade local, o fato de vendedores conhecerem seus clientes pelo nome, as condições personalizadas de atendimento, entre outros fatores, fazem com que haja sucesso na atuação do pequeno varejo.

Segundo Parente et al. (2008), os canais de pequeno varejo ampliam as possibilidades para os consumidores de baixa renda, uma vez que os mesmos preferem comprar de quem conhecem e confiam. Barki (2005, p. 40) cita que "a baixa renda tem uma identidade própria. Ela expressa uma racionalidade em que o preço é fundamental. No entanto, a variedade de produtos, o atendimento, o ambiente da loja e a confiança são decisivos na escolha de uma loja". Aspectos ligados à comunicação visual do ponto de venda, o formato de linguagem, a cultura empregada no ambiente, dialogo e respeito pelo consumidor, são fatores que, se bem trabalhados, tendem a gerar uma relação favorável, gerando um sentimento de identidade comum (BARKI, 2005).

Segundo Parente et al. (2008, p.58), “a percepção desempenha um papel central na avaliação do valor conferido por uma loja a seus produtos e serviços". Dada a hierarquia de valores peculiar dos consumidores de baixa renda, é fundamental que se compreenda quais os fatores que modelam a sua percepção e se desenhe ações no ponto de venda nesse sentido. Na visão de Barki (2005, p.40), "as lojas que conseguirem integrar com competência as diversas variáveis do composto varejista, reforçando a autoestima do consumidor, facilitando e valorizando a sua experiência de compra terão maior sucesso".

\section{3.}

\section{Relevância do consumo de serviços de telefonia móvel para o consumidor de baixa renda}

Estudo conduzido por Alves (2006) ressalta a importância do uso de celulares por consumidores de baixa renda. "Os entrevistados afirmaram que o celular ajudou a aumentar as oportunidades de emprego ou mesmo empreender 
um negócio próprio" (ALVES 2006, p. 80). Outros estudos apresentaram a relação direta entre o avanço da telefonia e o crescimento econômico e de renda nas classes menos favorecidas (BOYLE, 1998; BAYES, 2001; FORESTIER et al., 2002; RAMÍREZ \& RICHARDSON, 2005). Forestier et al. (2002) sugerem que o avanço das telecomunicações possui correlação com o avanço econômico dos países, apresentando alguns casos em que a telefonia proporcionou uma melhora na qualidade de vida da população de baixa renda local e incremento na renda familiar das mesmas.

Mariscal (2005) aborda que, de fato, há uma expectativa de melhoria na qualidade de vida e inclusão social dos menos favorecidos após avanço das telecomunicações em países pobres. Entretanto, alerta que há o risco de aumentarem as desigualdades entre as classes menos favorecidas e as demais caso os indivíduos de baixa renda não possuam acesso aos avanços ligados à tecnologia.

Segundo Prahalad (2005), o público de baixa renda possui diferentes prioridades, consideradas por vezes como luxo. É comum que deixem de investir em questões básicas, como saneamento e melhorias em suas habitações, para investir em produtos e serviços que facilitem suas vidas, como eletrodomésticos (batedeiras, aspirador de pó, etc.) e telefonia. Contrapondo o mito de que o segmento de baixa renda resiste a novos produtos, quando, na realidade, existem poucos produtos desenvolvidos para seu modo de vida e circunstâncias. A facilidade de uso de novas tecnologias como celulares e a conectividade desse consumidor demonstram esse fato (PRAHALAD, HAMMOND, 2002; PRAHALAD, 2005).

Segundo Prahalad (2005), isso se explica pelo fato de as empresas de telecomunicações oferecerem serviços de telefonia pré-paga, viabilizando o acesso desse público ao consumo e proporcionando sentimento de inclusão.

Segundo Alves (2006):

"O setor de telefonia móvel passou da fase movida pela preocupação centrada na tecnologia para uma maior atenção nas necessidades do mercado, procurando desenvolver conteúdos e serviços de interesse dos consumidores. Com o amadurecimento do mercado, as operadoras não podem apenas oferecer maior capacidade de rede respondendo a um crescimento estável. Ao contrário, devem atender necessidades especificas de diferentes grupos de consumidores, com aplicações inovadoras e pacotes específicos de serviços de valor agregado (apud BOHLIN et al., 2004, p.21). 
"Para o consumidor de baixa renda, ganhar acesso a novas tecnologias e bons produtos desenvolvidos para suas necessidades permite a eles dar um passo largo em direção à melhoria de qualidade de vida" (PRAHALAD, 2005, p. 106). Tal melhoria é percebida de maneira latente, segundo Silva e Parente (2007), pois inúmeros consumidores de baixa renda preferem alimentar-se pior a deixar de adquirir itens que consideram imprescindíveis, tais como o celular.

O acesso a telefonia e internet permitiu que o público de baixa renda pudesse estar conectado com as empresas que admiram e cujas marcas eles aspiram, e que possam estabelecer novos padrões de comunicação em ambientes fora dos limites da comunidade em que estão inseridos (PRAHALAD, 2005).

Outro ponto destacado por Prahalad (2005) é que consumidores de baixa renda aceitam bem o avanço e as inovações tecnológicas. A utilização de novas tecnologias permitiu que mudassem os parâmetros que norteiam suas atividades diárias. Exemplo disso é o acesso à consulta em bolsas de valores das principais capitais financeiras para viabilizar uma precificação mais adequada aos produtos que produzem em zonas rurais. Antes disso, o produtor rural ficava à mercê do comprador, que muitas vezes era quem determinava o preço que queria pagar. Hoje, o produtor já consegue cobrar de forma justa pelo produto, bem como tem a possibilidade de ofertar suas mercadorias para um mercado inacessível se não fosse pela tecnologia. Como não possuem processos eficientes, este é um público mais propenso a inovações e mudanças comportamentais. 


\section{3 \\ Metodologia}

O capítulo em questão expõe a metodologia de pesquisa adotada. $\mathrm{O}$ mesmo está dividido em cinco itens, sendo eles: tipo de pesquisa, seleção dos entrevistados, procedimento de coleta dos dados, procedimento de análise dos dados e limitações da metodologia.

\section{1.}

\section{Tipo de pesquisa}

O presente estudo busca, por meio de uma pesquisa exploratória, analisar os fatores que permeiam a relação de troca entre consumidores de baixa renda e bancas de jornal na aquisição de produtos de telefonia pré-paga.

"O objetivo da pesquisa exploratória é explorar ou fazer uma busca em um problema ou em uma situação a fim de oferecer informações e maior compreensão." (MALHOTRA 2004, p. 59). Optou-se por esse tipo de pesquisa uma vez que, embora existam muitos estudos que abordam o comportamento de compra dos consumidores de baixa renda relacionados a telefonia móvel e varejo, há carência de estudos acerca da relação entre bancas de jornais e o consumidor de telefonia pré-paga.

Com o objetivo de aumentar a compreensão acerca do objetivo do presente estudo, três fatores principais foram determinantes para a escolha do tipo de pesquisa:

1. Pesquisas qualitativas permitem que sejam abordados outros assuntos dentro do tema estudado (CHIKWECHE; FLETCHER, 2012);

2. Já que não há um vasto conhecimento acerca do tema, torna-se mais aderente a pesquisa qualitativa (SCHWANDT, 2006);

3. A abordagem qualitativa é capaz de explorar os significados associados as ações dos indivíduos (SCHWANDT, 2006). 
Malhotra (2004) explica que as entrevistas em profundidade podem em três formatos: entrevistas estruturadas, não estruturadas e semiestruturadas. Malhotra (2004) aborda que o modelo de entrevista semiestruturada possibilita que o entrevistado expresse com maior facilidade suas opiniões. Para a presente pesquisa optou-se pelo modelo semiestruturado.

A escolha adequada do modelo de pesquisa é extremamente relevante, uma vez que, segundo Malhotra (2004), a pesquisa de marketing é uma investigação sistêmica que tem a capacidade de orientar decisões empresariais.

\section{2.}

\section{Seleção dos entrevistados}

A pesquisa em questão limitou-se a pesquisar consumidores de baixa renda da cidade do Rio de janeiro, usuários de telefonia pré-paga e compradores de serviços de telefonia pré-paga em bancas. O critério adotado para a classificação sócio-econômica dos entrevistados foi o do IBGE, que divide a população em cinco classes sociais, conforme ilustrado no Anexo I.

Não há um consenso sobre o pertencimento da classe $\mathrm{C}$ à base da pirâmide. Embora as pesquisas sobre a baixa renda tenham avançado no Brasil, autores ainda não conseguiram definir com exatidão o segmento e chegar a um consenso. Estudiosos defendem que há uma dificuldade para definição teórica e limitação da baixa renda. Segundo Prahalad (2005), pode haver mudanças de comportamento de consumo da baixa renda de acordo com a região onde vivem, o país e a classe social em que se enquadram.

Segundo Chauvel e Mattos (2008), os grandes centros urbanos nacionais reúnem pessoas que pertencem à classes sociais distintas. Chauvel e Mattos (2008) apresentam que ainda que pessoas de classes menos favorecidas, como a classe C, vivam próximas as de classe mais abastada, há um elevado comprometimento de suas rendas com necessidades básicas, limitando o acesso dessas pessoas ao consumo. Uma vez que a presente pesquisa se passa na cidade do Rio de janeiro, onde há elevada concentração de comunidades e alto contraste social, a presente pesquisa assume como consumidor de baixa renda os indivíduos classificados nas classes C, D e E, em consonância ao posicionamento teórico de Chauvel e Mattos (2008). 


\section{3.}

\section{Procedimento de coleta de dados}

A coleta dos dados ocorreu no mês de fevereiro de 2018 e foi conduzida através de entrevista com a utilização de roteiro para auxilio da condução. O procedimento de coleta de dados das pesquisas foi realizado presencialmente, em bancas de jornal, com o consenso dos proprietários das mesmas. A pesquisa foi dividida em duas etapas, sendo uma de observação da interação do consumidor de baixa renda e o ponto de venda; e a outra uma etapa de entrevista direta com o mesmo, que se subdivide em dois momentos: identificação do perfil do consumidor e entrevista em profundidade. A coleta de dados foi exclusivamente realizada por meio de entrevistas com os consumidores do perfil desejado para a pesquisa, não sendo abordados consumidores fora do perfil.

A etapa de observação buscou coletar informações sem a influência de um agente externo, uma vez que o consumidor até então não tinha o conhecimento de que estava sendo observado, além de coletar insumos das relações de troca entre consumidor e jornaleiro que pudessem apoiar uma melhor compreensão do problema de pesquisa. Para isso, além do comportamento de compra como um todo, foram observados alguns comportamentos específicos como:

$>\mathrm{O}$ consumidor antes de entrar busca informação através do merchandising disposto no PDV (ao menos olha)?

O varejista oferece algum produto agregado?

O consumidor apresentou indícios de que conhece o varejista? (Chamou pelo nome, falou de situações passadas, tratamento próximo ou informal)

A identificação do consumidor de telefonia se dava no ato da solicitação do produto de telefonia pré-pago e a observação era conduzida à distância sem o conhecimento de que estava sendo observado. Somente após a aquisição do chip pré-pago junto ao varejista, os consumidores foram abordados pelo pesquisador para responderem à pesquisa, no ambiente externo ao ponto de venda.

Foi utilizado como instrumento de condução da entrevista um roteiro com as principais perguntas a serem realizadas ao entrevistado, conforme Anexo III. O roteiro baseou-se em perguntas com a finalidade de identificar o perfil do entrevistado e explorar os significados associados ao objetivo de pesquisa, tais como: 
Por que você optou por comprar o chip em uma banca de jornal?

Antes de entrar na banca, você já sabia que aqui vendia chip?

Quais são os fatores que levam você a comprar um produto em uma banca de jornal ao invés de comprar em outros locais que tenham o mesmo produto?

A formulação das perguntas do roteiro semi-estruturado se basearam nas pesquisas abordadas no referencial teórico desse estudo. Com base nos estudos de alguns autores buscou-se explorar o entendimento de algumas questões específicas que enriqueceriam o alcance do objetivo de pesquisa, como:

- Os fatores associados à relação custo/benefício que dimensionam a equação de valor proposta por Parente et al (2008) para a baixa renda;

$\mathrm{O}$ entendimento de fatores comportamentais que caracterizam a baixa renda brasileira como: conservadorismo acima da média, o gosto pela fartura, a baixa autoestima, a dignidade, a preferência por lojas da vizinhança, a flexibilidade de crédito e o contato pessoal (BARKI, 2005);

O aprofundamento no entendimento da afirmação: "a atuação no mercado de baixa renda é realizada com base em mitos que não se comprovam na prática.” (BARKI, 2005, p. 5)

Os sentimentos de reciprocidade e confiança que permeiam de forma relevante as relações sociais desse grupo, evidenciados pelo sucesso de varejos de pequeno porte com esse público (PARENTE et al., 2008);

Foram realizadas muitas perguntas abertas, com o objetivo de aprofundar ao máximo o entendimento dos significados associados pelos consumidores. Segundo Malhotra (2001):

As perguntas abertas são boas como primeiras perguntas sobre um tópico. Permitem ao entrevistado expressar atitudes e opiniões gerais que irão ajudar o pesquisador a interpretar suas respostas a perguntas estruturadas. As perguntas não-estruturadas têm, sobre a resposta, uma influência tendenciosa muito menor do que as perguntas estruturadas. Os entrevistados têm liberdade de expressar quaisquer pontos de vista. Seus comentários e explicações podem dar ao pesquisador valiosas informações sobre o entrevistado. Daí serem as questões não-estruturadas úteis na pesquisa exploratória (MALHOTRA, 2001, p. 281). 
Segundo Malhotra (2001) as perguntas precisam ter uma ordem lógica e todas as questões relacionadas a determinado tópico serem formuladas antes de passar para o próximo tópico. O presente roteiro de pesquisa foi construído com base nessa teoria.

Foram realizados dois pré-testes do roteiro de entrevistas com consumidores do perfil desejado, a partir dos quais foi possível perceber que seria necessário acrescentar algumas perguntas ao instrumento de coleta de dados antes de começar a pesquisa, tais como:

Você costuma comprar outros produtos nesta banca?

Antes de realizar a compra do chip, você lembra de ter visto algum material de comunicação falando sobre o produto que você comprou?

Fale sobre de que forma o atendimento do jornaleiro interferiu na sua compra.

Todas as entrevistas foram gravadas com o consentimento dos entrevistados, com o objetivo de garantir a captura completa de todas as informações fornecidas. Com a finalidade de reduzir possíveis constrangimentos por parte do entrevistado, não foi informado no momento da abordagem que a pesquisa tem como foco o público de baixa renda. Assim, quando o entrevistado foi questionado quanto à sua renda familiar mensal, foi-lhe apresentado uma tabela que não continha a classificação por classe social, pedindo que o entrevistado informasse em qual faixa de renda o mesmo se enquadrava dentro de uma variação de 1 a 5, sendo 1 a menor renda e 5 a maior renda, conforme Anexo II.

A fim de evitar vieses, buscou-se garantir diversidade entre homens e mulheres e diferentes idades, além de variados locais na cidade do Rio de Janeiro, compreendendo as áreas da Zona Oeste, Zona Norte e Centro da cidade. Buscouse ter uma coleta das entrevistas em diferentes horários e dias da semana, a fim de reduzir os vieses no perfil do consumidor.

O perfil dos entrevistados segue descrito na tabela 1: 


\begin{tabular}{|c|c|c|c|c|c|c|c|c|c|c|}
\hline$\#$ & Data & Ponto de venda & Local & Nome entrevistado & Profissão & Classe social & Estado Civil & Sexo & Idade & Bairro residencia \\
\hline 1 & $01 / 02 / 2018$ & Banca da praça & Madureira & Isabel costa & ATENDENTE & D & Casado & F & 37 & MADUREIRA \\
\hline 2 & $05 / 02 / 2018$ & Banca das irmas & Bangu & Alexandre batista & Servente & D & Casado & M & 42 & BANGU \\
\hline 3 & $05 / 02 / 2018$ & Banca das irmas & Bangu & Valquiria lemos & Domestica & D & Solteiro & F & 30 & BANGU \\
\hline 4 & $06 / 02 / 2018$ & Banca dona vera & Taquara & Bruno fernandes & Pedreiro & D & Solteiro & M & 33 & TAQUARA \\
\hline 5 & $07 / 02 / 2018$ & Banca do didiu & Campo grande & Rafael simões & Vendedor & C & Solteiro & M & 28 & PACIENCIA \\
\hline 6 & $07 / 02 / 2018$ & Banca Pai e Filho & Campo grande & Leila moraes & Do lar & D & Casado & F & 52 & CAMPO GRANDE \\
\hline 7 & $08 / 02 / 2018$ & Banda praça XV & Centro & Wagner souza & Garçom & C & Casado & M & 27 & MEIER \\
\hline 8 & $08 / 02 / 2018$ & Banda praça XV & Centro & Roberta Maria Vieira & Vendedor & C & Casado & F & 57 & SANTISSIMO \\
\hline 9 & $08 / 02 / 2018$ & Banda praça XV & Centro & Maria angelica lins & ATENDENTE & D & Casado & F & 41 & VARGEM GRANDE \\
\hline 10 & $21 / 02 / 2018$ & Banca Pai e Filho & Campo grande & Bruna lopes ferreira & Domestica & D & Casado & F & 38 & GUARATIBA \\
\hline 11 & $28 / 02 / 2018$ & Banca Pai e Filho & Campo grande & Everton silva teles & Vendedor & D & Solteiro & M & 25 & ITAGUAI \\
\hline
\end{tabular}

Tabela 1: Perfil resumido dos entrevistados

Fonte: Própria

O perfil de todos os entrevistados estava dentro do desejado, consumidores de telefonia pré-paga pertencentes a baixa renda. A faixa etária dos entrevistados foi entre 25 a 52 anos, variando entre homens e mulheres, solteiros e casados e moradores de bairros pertencentes ao município do Rio de janeiro.

\section{4.}

\section{Procedimento de análise de dados}

O presente estudo se baseou em uma análise sistemática dos dados, fundamentada nas transcrições das entrevistas. As onze entrevistas realizadas foram revisadas na íntegra e destacados os elementos mais relevantes para um melhor entendimento do problema de pesquisa. Como resultado, procurou-se categorizar os conteúdos coletados em consonância com as teorias apresentadas no referencial teórico, como:

1. Localização e Conveniência

2. Relação interpessoal e confiança

3. Flexibilidade de crédito

4. Estratégia de comunicação

Após essa categorização, foi realizada uma releitura das entrevistas e a partir do confronto entre os elementos chave selecionados e a teoria se tornou possível extrair uma análise mais detalhada.

A fim de capturar os vínculos emocionais presentes na relação com a banca de jornal para enriquecer a análise, foi realizada uma releitura buscando capturar além das palavras propriamente ditas pelos entrevistados. 


\section{5.}

\section{Limitações do método}

A metodologia escolhida para a pesquisa apresenta algumas limitações evidentes.

Segundo KATES (1998), não se pode fazer generalizações pois esse tipo de pesquisa é limitada ao grupo dos entrevistados. Naturalmente a presente pesquisa consegue apenas apresentar pressupostos culturais que podem auxiliar no entendimento sobre a forma como os fenômenos são construídos.

Creswell (2003) aborda a possibilidade de viés na interpretação dos dados por parte do pesquisador como outro fator de limitação para a metodologia aplicada. Ainda que hajam formas de minimizar os viéses, a interpretação do pesquisador é carregada de valores específicos do mesmo e uma limitação de conhecimento de pode variar muito entre indivíduos. 


\section{4}

\section{Análise dos dados}

No presente capítulo, é apresentada a análise dos dados, dividida em quatro seções, a saber: (1) Localização e conveniência das bancas de jornal; (2) Relação interpessoal e confiança no Ponto de Venda; (3) Flexibilidade de crédito disponibilizada no ponto de venda; e (4) Estratégia de Comunicação do ponto de venda.

\section{1.}

\section{Localização e conveniência das bancas de jornal}

Embora se tratem de fatores diferentes, verificou-se que os consumidores de baixa renda entrevistados, no que se refere à aquisição de produtos de telefonia pré-paga, percebem valor quando localização e conveniência das bancas podem ser encontradas juntas. Alguns depoimentos revelam que a escolha da banca se deu por sua localização, próxima ao domicílio ou o trabalho do entrevistado, e que a compra do chip pré-pago de telefonia aconteceu nesse estabelecimento comercial porque, além da proximidade, é um estabelecimento que oferece uma variedade atraente de produtos e serviços, como se verifica nos trechos de entrevistas a seguir:

Eu já compro nessa banca de jornal há mais de cinco anos, desde quando me mudei para Bangu. Ela fica perto do meu ponto de ônibus (entrevistado 2).

Só compro aqui porque é pertinho do ponto do meu ônibus (entrevistado 3).

O call center que eu trabalho é na porta. Por isso, comprei aqui na banca (entrevistado 9).

Aqui, normalmente tem tudo. O Meia Hora (jornal), que eu vejo depois do jogo, e chip também. Eu só não vejo muitas bancas vendendo bebidas, mas tem em muitas também (entrevistado 4).

Eu compro no Didiu porque sei que tem as coisas que preciso. Mas, não costumo comprar muito jornal, então não conheço várias bancas (entrevistado 5). 
Barbosa (2009) afirma que consumidores de baixa renda são mais propensos a adquirirem seus créditos telefônicos em pontos de venda do pequeno varejo, tais como bancas de jornais, do que em lojas de operadoras de telecomunicações. Nesse sentido, os depoimentos dos entrevistados foram relevantes para entender a banca de jornal como um importante canal de vendas do pequeno varejo, não apenas para a venda de recarga de telefonia celular, mas também para a aquisição de chips pré-pagos.

Tal fato já havia sido evidenciado em pesquisas realizadas pelo instituto Data Popular (2004), Booz Allen Hamilton (2003) e Latin Panel (2004) sobre consumidores de baixa renda no Brasil, que indicam a preferência desses indivíduos por lojas próximas ou em sua vizinhança, além do contato pessoal com o jornaleiro, fator esse que é mais detalhado na próxima seção.

\section{2. \\ Relação interpessoal e confiança no ponto de venda}

Parente et al. (2008) mencionam a existência de uma relação de confiança e reciprocidade entre o consumidor de baixa renda e o ponto de venda de pequeno varejo, o que leva este indivíduo a realizar suas compras em locais conhecidos por eles. Um dos principais fatores geradores desse sentimento é a relação pessoal que desenvolvem com os vendedores (ou, no caso do presente estudo, com o jornaleiro), que passam a atendê-los de maneira mais amistosa, informal, agradando esse público. Isso ficou evidente nos depoimentos a seguir:

Quem vai mais em banca mesmo é o meu marido. Lá perto de casa, tem um jornaleiro que ele compra jornal, fica todo final de semana lá quase duas horas batendo papo. Bom que eu faço comida domingo em paz (entrevistado 8).

Não sei o nome dele (jornaleiro). Mas, sei que ele é bem gente fina e trabalha aqui na praça há uns 10 anos (entrevistado 1).

Didiu é das antigas aqui no Calçadão. Muito parceiro. Tem nome na área aqui (entrevistado 5).

Percebe-se que o consumidor não enxerga o ponto de venda como um estabelecimento comercial, mas sim como um local onde "alguém" vende um produto que ele precisa. Há uma pessoalidade focada na pessoa do jornaleiro, e não no ponto de venda em si. Em alguns casos, a frequência com que o ponto de venda é visitado, por se tratar de um ponto de conveniência onde se encontra produtos de consumo diário, cria uma relação pessoal entre vendedor e cliente. 
Segundo Soares (2014), “a convivência entre proprietários e clientes (em bancas de jornal), com o tempo, vai construindo uma relação de afeição entre as pessoas".

A relação entre as partes não é necessariamente profunda; diversas vezes o consumidor conhece o jornaleiro, mas não sabe seu nome. Contudo, sente-se ligado a ele a tal ponto que opta por comprar o chip naquela banca para "ajudar" o mesmo, conforme demonstram os depoimentos a seguir:

Vou te falar que as meninas aqui são muito parceiras e também é o mesmo preço das lojas da Claro. Aqui, eu dou uma moral pra elas (entrevistado 2).

Se for um produto que tem aqui, não faz sentido eu ir em outro lugar. Até pra dar uma moral pra ele. Já trabalha há muito tempo aqui, rala bastante (entrevistado 9).

André é parceiro demais. Atendimento é bom. O cara sabe o que você gosta e te trata bem. Não iria comprar em outro lugar podendo comprar com ele (entrevistado 11).

A grande maioria dos consumidores já chega ao ponto de venda com a decisão tomada sobre qual chip comprar. Embora alguns dos consumidores tenham pedido indicação, notou-se que o jornaleiro normalmente não indicava uma operadora especifica. Contudo, o jornaleiro apresentou forte influência na venda de outros produtos de valor agregado, como a recarga. Em boa parte dos casos, o mesmo oferecia produtos agregados, que eram aceitos pelos consumidores.

Os clientes que realizaram esse tipo de aquisição procuraram a banca especificamente para esta finalidade, e em alguns casos acabou adquirindo também outros produtos, como balas, cigarros e bilhetes de transporte. O contrário não aconteceu em nenhum dos casos observados: não houve clientes que tenha procurado a banca de jornal para adquirir outro produto e acabaram comprando um chip de telefonia, o que pode ser uma evidência de que este tipo de produto não é comprado por impulso no ponto de venda.

A referência de local de consumo de produtos de telefonia pré-paga para o consumidor de baixa renda em bancas de jornal é tamanha que muitos consumidores entram em bancas de jornal que não conhecem em busca do produto. Pode-se notar também que em alguns casos mesmo dentro de um ponto de venda nunca visitado anteriormente o consumidor de baixa renda está suscetível a ser influenciado pelo jornaleiro em sua compra de produtos de telefonia pré-paga. 


\section{3. Flexibilidade de crédito disponibilizada pelo ponto de venda}

Segundo Barki (2005), outro fator comportamental que caracteriza o segmento de baixa renda brasileiro é a busca por flexibilidade de crédito quando consomem produtos e serviços. Parente et al. (2008) também citam essa característica como sendo um fator que empresas devem atentar para oferecer uma boa relação custo/benefício a esses consumidores.

No que tange à aquisição de serviços pré-pagos de telefonia, verificou-se uma oportunidade no que tange às formas de pagamento. Todas as compras que os entrevistados fizeram nas bancas de jornal foram realizadas em dinheiro, embora grande parte deles tenha mencionado que preferiria pagar com o cartão. Contudo, esse não é um fator que inviabilize a compra, já que a maioria desses consumidores pressupôs que o local não aceitava outra forma de pagamento, conforme indicam os relatos destacados a seguir:

Não aceita cartão. É tudo dinheiro aqui. Seria melhor no cartão (entrevistado 7).

Eu adoraria pagar no cartão. Mas, você nunca encontra lugares que aceitam. Aqui é só dinheiro mesmo (entrevistado 9).

Vou na grana mesmo, porque acho que não tem outro jeito. Banca não tem cartão. Pago na grana, que é baratinho (entrevistado 2).

Porém, a existência de uma flexibilização no momento do pagamento fica evidente quando alguns entrevistados relatam que compram "fiado" na banca. Essa forma de crédito é baseada na confiança estabelecida entre o jornaleiro e o consumidor. Contudo, é importante ressaltar que, neste caso, é o jornaleiro quem confia que o consumidor voltará para efetuar o pagamento, ainda que esse não deixe nenhuma garantia, exceto a sua palavra, conforme explica o entrevistado 2: "Às vezes, pego jornal fiado com elas e pago na volta do serviço. Elas são parceiras".

Segundo Parente et al. (2008), as condições personalizadas de atendimento são um dos fatores que fazem com que o pequeno varejo seja bem sucedido em suas vendas a consumidores de baixa renda. Esse público é sensível a ações que reforcem os sentimentos de pertencimento, reciprocidade e confiança, valorizando estabelecimentos comerciais que os ofereçam tais benefícios. 


\section{4. \\ Estratégia de comunicação do ponto de venda}

Barki (2005) aborda a importância da adequação da estratégia de comunicação no ponto de venda para alcançar o consumidor de baixa renda. É evidente, pelo discurso destes consumidores, que há um conhecimento prévio e arraigado de que a banca de jornal é um ponto de venda de chip de telefonia. Declarações como "todas as bancas vendem chip e recarga" (entrevistado 1) e “chip só tem nesses lugares" (entrevistado 10) evidenciam esse conhecimento.

Entretanto, embora nem todos os entrevistados tenham relatado que entraram no ponto de venda porque viram a sinalização de venda de produtos de telefonia, ao serem questionados, todos tiveram acesso à comunicação, conforme indicam os depoimentos a seguir:

Sim, tem um monte desses cartazes aqui. Deu pra reparar sim, antes de entrar (entrevistado 9).

Tinha o cartaz da TIM também, com a propaganda que te falei (entrevistado 10).

Eu já sabia que tinha chip aqui porque tinha visto antes. Mas, reparei na propaganda da Claro, que estava na porta (entrevistado 8).

É possível inferir, portanto, que o material de comunicação no ponto de venda é importante para sinalizar a este consumidor que a banca de jornal é um local de venda deste tipo de serviço. 


\section{5 \\ Conclusão, recomendações gerenciais e sugestões de estudos futuros}

Este estudo teve como objetivo principal analisar o que leva consumidores de baixa renda a utilizarem bancas de jornal como um local de aquisição de produtos pré-pagos de telefonia móvel. Para isso, foram feitas 11 entrevistas em profundidade com consumidores de baixa renda em bancas de jornal na cidade do Rio de Janeiro. Após realizar a análise dos dados, foi possível chegar a algumas conclusões.

Pode-se notar que as bancas de jornal se destacam na maioria dos atributos de percepção de valor para o cliente do modelo proposto por Parente et al. (2008), conforme tabela 2. Esse fato corrobora a forte participação deste tipo de ponto de venda como canal de comercialização de produtos de telefonia móvel pré-paga.

\begin{tabular}{|l|l|}
\hline $\begin{array}{l}\text { Fatores associados a } \\
\text { percepção de valor } \\
\text { (Modelo proposto por } \\
\text { Parente } \text { et al. } \text { (2008)) }\end{array}$ & $\begin{array}{l}\text { Percepção capturada nas pesquisas relacionada aos } \\
\text { fatores de percepção de valor do modelo de } \\
\text { Parente } \text { et al. (2008) }\end{array}$ \\
\hline Produtos e serviços & $\begin{array}{l}\text { A banca é percebida como um local onde se } \\
\text { encontra de tudo. }\end{array}$ \\
\hline Atendimento & $\begin{array}{l}\text { O atendimento é percebido como próximo e } \\
\text { desperta sentimentos como confiança e } \\
\text { reciprocidade. }\end{array}$ \\
\hline Facilidade de crédito & $\begin{array}{l}\text { O modelo de pagamento proposto é conhecido e } \\
\text { aceito na maioria dos casos pelos consumidores. } \\
\text { Modelos como o fiado existem e são percebidos } \\
\text { como um fator que reforça a relação de confiança. }\end{array}$ \\
\hline Ambiente de loja & $\begin{array}{l}\text { O ambiente de loja atende a expectativa de } \\
\text { praticidade e agilidade dos consumidores. }\end{array}$ \\
\hline Proximidade física & $\begin{array}{l}\text { A localização física é percebida como um dos } \\
\text { principais diferenciais, ajudando a reforçar } \\
\text { inclusive o sentimento de confiança devido a } \\
\text { frequência com que se visitam os mesmos pontos } \\
\text { de venda. }\end{array}$ \\
\hline Tempo & $\begin{array}{l}\text { As bancas são percebidas como um canal que } \\
\text { proporciona maior agilidade e conveniência para o } \\
\text { consumo, contribuindo positivamente para a } \\
\text { percepção do consumidor no fator tempo. }\end{array}$ \\
\hline
\end{tabular}




\begin{tabular}{|l|l|}
\hline Financiamento & Não se aplica. \\
\hline Riscos associados & $\begin{array}{l}\text { O latente sentimento de confiança apresentado nas } \\
\text { entrevistas minimiza significativamente a } \\
\text { percepção de riscos associados a compra nas } \\
\text { bancas de jornal. }\end{array}$ \\
\hline Psíquicos & $\begin{array}{l}\text { Os sentimentos de reciprocidade e confiança } \\
\text { desenvolvidos na relação entre ponto de venda e } \\
\text { consumidor potencializam positivamente os } \\
\text { fatores psíquicos envolvidos nessa relação. }\end{array}$ \\
\hline
\end{tabular}

Tabela 2: Modelo percepção de valor no varejo aplicado em bancas.

Fonte: Própria

Ficou evidenciada a capacidade de influência do jornaleiro na decisão de compra do consumidor final, fato que se pode atribuir, em grande parte, ao sentimento de confiança e reciprocidade na relação com o consumidor de baixa renda. $\mathrm{Na}$ análise das entrevistas ficou evidente o quanto o jornaleiro e o consumidor de baixa renda costumam desenvolver essa relação pessoal. Isso é favorecido pela localização das bancas de jornal, que em geral estão situadas em regiões residenciais, pontos de alto fluxo e pontos de presença frequente dos consumidores de baixa renda, o que provoca uma maior recorrência no contato com os consumidores.

Os atributos crédito e forma de pagamento não se apresentaram como críticos de sucesso para a aquisição dos produtos no ponto de venda. Entretanto, podem se apresentar como diferenciais quando disponibilizados da forma correta ao consumidor. Todos os pontos de venda entrevistados trabalhavam apenas com dinheiro como forma de pagamento. Em contrapartida, grande parte dos consumidores citou ter interesse em utilizar outros métodos de pagamento.

Conclui-se que as bancas de jornal são referência para consumo de produtos de telefonia móvel pré-paga por consumidores de baixa renda, uma vez que, na visão destes consumidores, atendem de maneira positiva parte relevante dos atributos que determinam a percepção de valor, justificando também o sucesso de vendas do segmento no setor de produtos de telefonia móvel pré-paga. Oportunidades para as empresas de telecomunicações e os varejistas em geral, como apresentadas no estudo, podem existir. 


\section{1. Recomendações gerenciais}

Segundo Golveia (2015), os jornais impressos e periódicos entraram em decadência após a massificação dos meios eletrônicos de notícia. Por consequência, o segmento de bancas de jornal precisou se reinventar, passando a comercializar produtos de outros segmentos, aumentando seu composto de produtos e posicionando-se como loja de conveniência. Acompanhando essa tendência, alguns segmentos da indústria conseguiram se consolidar dentro desse tipo de ponto de venda e atualmente a banca de jornal é referência para os consumidores como um local para a aquisição de seus produtos. Segundo Golveia (2015), os jornaleiros já compõem mais da metade de suas receitas a partir de outros segmentos.

As entrevistas evidenciaram a forte associação para os consumidores entre as bancas de jornal e os produtos de telefonia móvel pré-paga. Esse fato pode ser relevante para a indústria de telecomunicação em uma eventual intenção de aumento do sortimento de produtos direcionados às classes de baixa renda, como, por exemplo, planos Controle (planos pós pagos com franquias fixas), acessórios telefônicos, entre outros.

Outro ponto de oportunidade empresarial é a questão da propaganda veiculada neste tipo de ponto de venda. Uma vez que os consumidores já entendem as bancas de jornal como um local onde há produtos de telefonia prépaga, abre-se a oportunidade de revisão do objetivo e tipo de comunicação do merchandising utilizado pelas mesmas atualmente. Evidenciou-se que o consumidor notava a existência do merchandising, entretanto não havia lido a comunicação nele veiculada. Sem exceção, todos os materiais publicitários veiculavam conteúdos ligados à oferta dos planos pré-pagos, quantidade de minutos, pacotes de internet e preço. Contudo, o consumidor não absorveu o conteúdo. Sendo assim, este tipo de comunicação pode ser voltado para construção de marca e o veículo de divulgação da oferta passaria a ser o próprio jornaleiro, cuja opinião tem forte significado para este tipo de consumidor. 
O grau de influência do jornaleiro com o consumidor de baixa renda e a relação de confiança estabelecida abre margem para discussão do modelo atual de relacionamento das operadoras com esse segmento de pontos de venda. Uma vez que já possuem alta representatividade no segmento e apresentam características que podem ser diferenciais nas relações de troca com os consumidores de baixa renda, merecem ser mais bem exploradas para se desenvolver um modelo de atuação mais adequado para esse segmento de pontos de venda.

\section{2.}

\section{Sugestões de estudos futuros}

A partir do escopo limitado da presente pesquisa e das oportunidades gerenciais apontadas, sugerem-se estudos futuros focados em dois âmbitos: relacionamento das operadoras de telefonia com o pequeno varejo e o relacionamento das operadoras de telefonia com o consumidor de baixa renda.

Assim como abordado no presente estudo com bancas de jornais, existe a oportunidade de um melhor entendimento do papel do pequeno varejo em geral nas relações de troca com clientes da baixa renda. Estudos nesse sentido podem auxiliar o setor de telecomunicações a compreender mais profundamente o papel desempenhado pelo ponto de venda e os anseios dos clientes de baixa renda, gerando iniciativas que possam melhorar o atendimento das necessidades dessa parcela de consumidores potencializando os negócios junto a este público ainda preterido pela indústria, mas com grande potencial de consumo.

Como apresentado, o mercado de telefonia pré-paga tem altíssima relevância para o segmento de telefonia, o que fortalece a necessidade de se conhecer mais profundamente o consumidor de baixa renda. Compreender os hábitos de consumo desse consumidor e seus anseios pode ajudar a direcionar ações gerenciais mais assertivas e eficientes. 


\section{Referências bibliográficas}

ALVES, C. E. A. Um estudo sobre o uso da telefonia celular nas classes de baixa renda. 2006. Dissertação (Mestrado em Administração de Empresas) Pontifícia Universidade Católica do Rio de Janeiro, Rio de Janeiro.

ALWITT, L. F.; DONLEY, T. D. Retail stores in poor urban neighborhoods. Journal of Consumer Affairs. v. 31, Issue 1, p. 139. Summer 97.

ANATEL (Brasil). Disponível em:

$<$ http://www.anatel.gov.br/Portal/documentos/sala_imprensa/28-10-2015--

12h4min26s-Brazil_Propostal_UIT_ICT_Report_final.pdf>. Acesso em 27 out. 2017.

Disponível em:

$<$ https://cloud.anatel.gov.br/index.php/s/cYiia4jXy6xg1Zj\#pdfviewer>. Acesso em 17 out. 2017.

. Disponível em: <http://www.anatel.gov.br/dados/destaque-1/283-

movel-acessos-maio>. Acesso em: 19 out. 2017.

ANDERSON, T. Exploding myths about Marketing to Ds and Es. Brand Strategy. Issue 162, p. 37. Aug. 2002.

BACHA, M. et al. O uso do celular na inclusão social e digital: uma análise de agrupamentos. 2005. Artigo - Associação Educacional Dom Bosco, Rio de Janeiro.

BARBOSA, P. B.; HOR-MEYLL, L. F.; MOTTA, P. C. O uso de celular prépago por consumidores de baixa renda. In: ROCHA, A.; SILVA, J. F. (org.) Consumo na base da pirâmide: estudos brasileiros. Rio de Janeiro: Mauad X, , p.113-132. 2009.

BARKI, E. Estratégias de Empresas Varejistas Direcionadas para a Baixa Renda: Um Estudo Exploratório. São Paulo, 2005.

BAYES, A. Infrastructure and rural development: insights from a Grameen Bank village phone initiative in Bangladesh. Agricultural Economics. Elsevier, v. 25, p. 261-272, 2001.

BOHLIN, E.; LEVIN, S. L.; SUNG, N. Special Issue on Growth in Mobile Communications. Telecommunications Policy, Elsevier Business and Management, p. 101-105, 2004. 
BOOZ ALLEN HAMILTON. Creating Value in Retailing for Emerging Consumers. Breaking Myths about Emerging Consumers -- Learning from Small Scale Retailers. An Exploratory Study conducted for the Coca-Cola Retail Research Center - Latin America. Junho 2003.

BRUNO, L. Cenários-Operadoras disputam clientes pré-pagos diante de queda do uso de vários chips. R7. 28 jan. 2016. Disponível em: < https://noticias.r7.com/economia/cenarios-operadoras-disputam-clientes-pre-

pagos-diante-de-queda-do-uso-de-varios-chips-28012016>. Acesso em: 27 out. 2017.

BOYLE, D. A mobile is a cow. New Statesman, ProQuest European Business, v. 11, n. 515, p. 33, 31 jul. 1998.

CHAUVEL, M. A.; MATTOS, M. P. A. Z. Consumidores de baixa renda: uma revisão dos achados de estudos feitos no Brasil. Cadernos Ebape, v. 6, n. 2, p. $1-16,2008$.

CHIKWECHE, T.; FLETCHER, R. Undertaking research at the bottom of the pyramid using qualitative methods - from theoretical considerations to practical realities. Qualitative Marketing Research: An International Journal, v. 15, n. 3, p. 242-267, 2012.

CRESWELL, J. W. Research design: qualitative, quantitative and mixed methods approaches. 2. ed. Thousand Oaks, Cal: Sage Publications, 2003.

DATA POPULAR. Comunicação Popular: Modo de Usar. <http://www.datapopular.com.br>. Seminário apresentado no GVcev em 17 de Junho de 2004.

FORESTIER, E.; GRACE, J.; KENNY, C. Can Information and Communication Technologies be Pro-poor?. Telecommunications Policy, Elsevier Business and Management, 2002.

FORUM EDITORIAL (Brasil). Disponível em: $<$ http://www.forumeditorial.com.br/wpcontent/uploads/2016/04/AnuarioTelecom2016.pdf>. Acesso em: 27 out. 2017.

GOLDMAN, A. Confined Shopping Behavior Among Low Income Consumers: An Empirical Test. Journal of Marketing Research(JMR). v. 15 Issue 1, p11. Feb. 78,

GOUVEIA, I.; BRAGA, B.; FONSECA, L.; NETO, E. De bancas de jornal à loja de conveniência: análise da adaptação às perspectivas do mercado. Disponível em:

$<$ http://www.revistahumanidades.com.br/arquivos_up/artigos/a108.pdf $>$. Acesso em: 28 out. 2017.

HAMMOND, A. et al. The Next Four Billion: Market Size and Business Strategy at the Base of the Pyramid. Washington, DC: World Resources Institute / International Finance Corporation, 2007. 
HISTORIA HOJE. Disponível em: < http://historiahoje.com/as-bancas-de-jornalestao-se-tornando-parte-da-memoria-das-cidades-brasileiras/>. Acesso em 30 out. 2017.

KEMPEN, L. V. Are the poor willing to pay a premium for designer labels? A field experiment in Bolivia. Oxford Development Studies, v. 32, Issue 2, p. 205. Jun 2004.

KUNREUZHER, H. Why the Poor May Pay More for Food: Theoretical and Empirical Evidence. Journal of Business, v. 46, Issue 3, p. 368. Jul73.

LATIN PANEL. Consumidores de Baixa Renda: Onde estão, quem são e o que consomem. Disponível em: <http://www.latinpanel.com.br $>$. Seminário apresentado no GVcev em 17 de Junho de 2004.

LOVELOCK, C. H. Services marketing. Upper Saddle River: Prentice Hall, 1996.

MALHOTRA, N. K. Pesquisa de Marketing: Uma Orientação Aplicada. 4.ed. Bookman,2004.

Pesquisa de Marketing: Uma Orientação Aplicada. Tradução: Nivaldo Montingelli Jr. e Alfredo Alves de Farias. 3. ed. Porto Alegre: Bookman, 2001.

MARISCAL, J. Telecommunications in Latin America. Telecommunications Policy, Elsevier Business and Management, 2005b.

MATOS, C. Internet no celular é o desejo no.1 das classes C, D e E. Folha de São Paulo, p. B5. 09/12/2011.

MELLO, G. Bancas de jornal viram lojas de conveniência. Rudge Ramos Jornal (on - line). Publicado em: 30/09/2011 09h24. 2011. Disponível em: $<$ http://www.metodista.br/rronline/rrjornal/2011/ed.970/bancas-de-jornal-viramlojas-de-conveniencia>. Acesso em: 28 out. 2017.

PARENTE, J. O varejo de alimentos para consumidores de baixa renda no Brasil. Projeto de Pesquisa NPP. 2005a.

.; LIMEIRA, T. M. V.; BARKI, E. Varejo para a baixa renda. Porto Alegre: Bookman, 2008.

PRAHALAD, C. K. A riqueza na base da pirâmide. Porto Alegre: Artmed, 2005.

RAMÍREZ, R.; RICHARDSON, D. Measuring the Impact of Telecommunication Services on Rural and Remote Comunities. Telecommunications Policy, Elsevier Business and Management, 2005.

ROSA, B. Brasileiros cortam os gastos com celular pré-pago. O Globo. 20 ago. 2016. Disponível em: <https://oglobo.globo.com/economia/brasileiros-cortam-osgastos-com-celular-pre-pago-19961265. Acesso em: 19 out. 2017 
. Celular: cartão pré-pago já vende mais fora dos pontos tradicionais. $\mathbf{O}$

Globo. 22 abr. 2014. Disponível em: $<$ https://oglobo.globo.com/economia/celular-cartao-pre-pago-ja-vende-mais-forados-pontos-tradicionais-12258517\#ixzz4wMqZb2HB>. Acesso em: 20 out. 2017.

SCHWANDT, T. Três posturas epistemológicas para a investigação qualitativa interpretativismo, hermenêutica e construcionismo social. In: DENZIN, N.; LINCOLN, Y. O planejamento da pesquisa qualitativa - teorias e abordagens. Porto Alegre: Artmed, 2006. 432p.

SILVA, L. F.; FIQUEIREDO, J. S.; SANTOS, B. Q. O ecossistema das bancas de jornal: um estudo sobre uma espécie em extinção. Revista Eletrônica em Gestão, Educação e Tecnologia Ambiental - REGET, Santa Maria, v. 19, n. 1, p. 80-95, jan./abr.2015.

SIMON, C. Classe C é maioria no mercado de Telefonia Celular. Exame, São Paulo. 08 out. 2013. Disponível em: <http://exame.abril.com.br/seudinheiro/classe-c-e-maioria-no-mercado-de-telefonia-celular/_>. Acesso em: 20 out. 2017.

SOARES, T.; CARDIM, N. Bancas de jornal são ponto de convivência entre proprietários e clientes. Publicado em: 29/09/2014 06h09. 2014. Disponível em: <http://www.correiobraziliense.com.br/app/noticia/cidades/2014/09/29/interna_ci dadesdf,449439/bancas-de-jornal-sao-ponto-de-convivencia-entre-proprietarios-eclientes.shtml>. Acesso em: 28 out. 2017.

TELEBRASIL (Brasil). Disponível em: <http://www.telebrasil.org.br/panoramado-setor/consulta-a-base-de-dados>. Acesso em: 19 out. 2017.

TELECO (Brasil). Disponível em: <http://www.teleco.com.br/ncel.asp > . Acesso em 15 out. 2017.

Disponível em: <http://www.teleco.com.br/comentario/com11.asp>.

Acesso em: 28 out. 2017.

VERGARA, S. Projetos e relatórios de pesquisa em administração. São Paulo: Atlas S. A. $11^{\circ}$ ed. 2009.

ZEITHAML, V. A. Consumer perceptions of price, quality and value: a meansend model and synthesis of evidence. Journal of Marketing, v. 52, n. 3, p. 2-22, July, 1988. 
Anexo I

\section{Classes Sociais por Faixas de Salário-Mínimo (IBGE)}

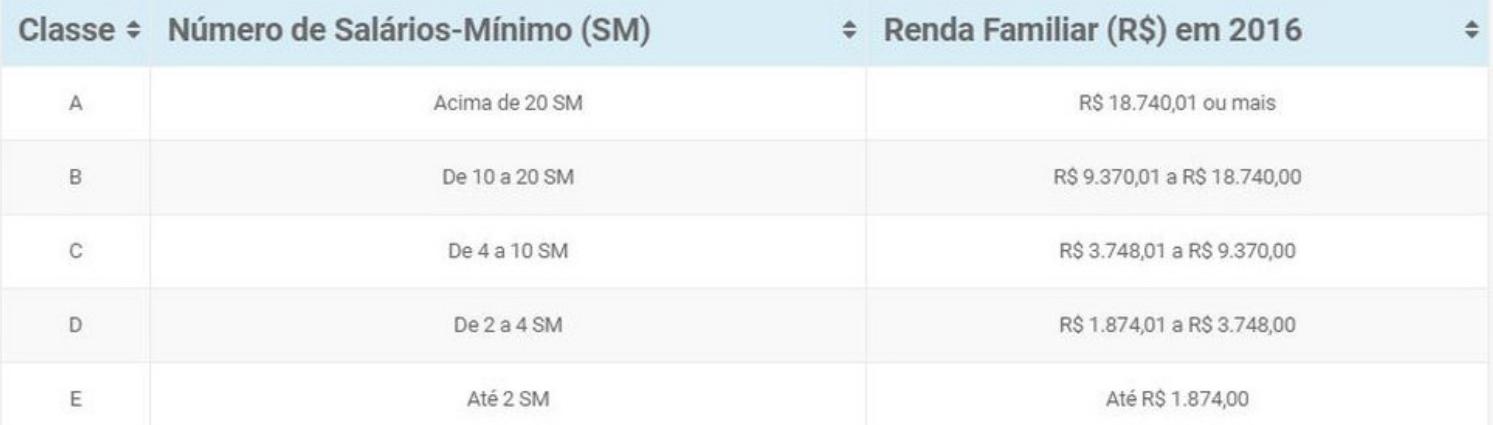




\section{Anexo II}

Faixa de renda familiar mensal

\begin{tabular}{ccc}
\hline $\begin{array}{c}\text { Faixa de } \\
\text { Renda }\end{array}$ & $\begin{array}{c}\text { Faixa de Renda em } \\
\text { Salários Mínimos (SM) }\end{array}$ & Faixa de Renda em $\mathbf{R} \$$ \\
\hline $\mathbf{1}$ & Até $2 \mathrm{SM}$ & Até $\mathrm{R} \$ 1.760,00$ \\
$\mathbf{2}$ & De 2 até 4 SM & $\mathrm{R} \$ 1.760,01$ até $\mathrm{R} \$ 3.720,00$ \\
$\mathbf{3}$ & De 4 até $10 \mathrm{SM}$ & $\mathrm{R} \$ 3.720,01$ até $\mathrm{R} \$ 8.800,00$ \\
$\mathbf{4}$ & De 10 até $20 \mathrm{SM}$ & $\mathrm{R} \$ 8.800,01$ até $\mathrm{R} \$ 17.600,00$ \\
$\mathbf{5}$ & Acima de $20 \mathrm{SM}$ & $\mathrm{R} \$ 17.600,01$ ou mais \\
\hline
\end{tabular}




\section{Anexo III}

\section{ROTEIRO SEMI-ESTRUTURADO}

\section{Observacão simples}

Serão observados prioritariamente os seguintes comportamentos referentes ao consumidor de baixa renda durante a compra do produto:

1) $O$ consumidor antes de entrar busca informação através dos merchans dispostos no PDV (ao menos olha)?

2) O consumidor pede diretamente algum chip em especifico ou busca se informar junto ao varejista qual a melhor para ele?

3) O varejista oferece algum produto agregado? Se sim qual? Foi aceito?

4) O pagamento é realizado de que forma? É oferecido opções de pagamento?

5) O consumidor comprou outros produtos que não sejam de telefonia? Quais?

6) O motivo principal da visita a banca era a compra do chip pré-pago?

7) O consumidor apresentou indícios de que conhece o varejista? (chamou pelo nome, falou de situações passadas, tratamento altamente próximo ou informal)

\section{Entrevista por pauta}

Bom dia/ boa tarde/ noite. Eu me chamo Roberto Braga, sou estudante da PUCRio e estou pesquisando sobre o consumidor de telefonia pré-paga. Gostaria de entrevistá-lo(a) sobre a sua experiência na compra do produto na banca de jornal. Antes de iniciarmos, gostaria de esclarecer que seu nome não será mencionado e você não será identificado na pesquisa. Também é importante informar que não há respostas corretas ou erradas. O objetivo é justamente entender quais são os pontos que você considera relevante para fazer sua compra. Sendo assim, pode ficar à vontade para mencionar qualquer informação que entender relevante.

Para facilitar a condução da conversa e evitar que eu te interrompa ou peça para repetir alguma informação, vou gravar a entrevista. Contudo, esse conteúdo será usado somente para a análise dos dados e não será divulgado. Podemos prosseguir desta forma? 
1) Observei que você adquiriu um chip pré-pago. Com que frequência você costuma trocar de chip?

2) Por que você optou por comprar o chip em uma banca de jornal?

3) O que fez com que você escolhesse essa banca de jornal especificamente?

4) Antes de entrar na banca, você já sabia que aqui vendia chip? Se sim, como sabia?

5) Você costuma comprar outros produtos nesta banca?

6) Você conhece o jornaleiro pelo nome? Fale sobre sua relação com o jornaleiro desta banca ou de outra onde você costuma comprar.

7) Quais os fatores que te levam a comprar um produto em uma banca de jornal ao invés de comprar em outros locais que tenham o mesmo produto?

8) O que levou você a escolher a operadora $X$ ?

9) Você já havia decidido que queria o chip desta operadora ou procurou maiores informações com o jornaleiro?

10) Antes de realizar a compra do chip, você lembra de ter visto algum material de comunicação falando sobre o produto que você comprou?

11) Fale sobre de que forma o atendimento do jornaleiro interferiu na sua compra.

12) Fale também sobre as formas de pagamento na banca de jornal. Qual a forma de pagamento que você prefere utilizar para comprar um chip?

13) A forma de pagamento é um fator que te levou a comprar na banca de jornal?

Dados Pessoais:

Qual o seu nome?

Qual o mês e ano do seu nascimento?

Qual o seu estado civil?

Qual a sua profissão?

Em que bairro você mora?

Em que bairro você trabalha?

Qual a sua faixa de renda familiar mensal? 


\section{Anexo IV}

\section{Pesquisa de campo}

Entrevistado

Data

Ponto de venda

Local

Nome entrevistado

Profissão

Classe social

Estado Civil

Sexo

Idade

Bairro residencia

1) O consumidor antes de entrar busca informação através do merchandising disposto no PDV (ao menos olha)?

2) $O$ consumidor pede diretamente algum chip em especifico ou busca se informar junto ao varejista qual é o melhor para ele?

2.1) Qual operadora

3) O varejista oferece algum produto agregado?

3.1)Se sim, qual?

3.2) Foi aceito pelo consumidor?

4) O pagamento é realizado de que forma?

4.1)É oferecido opções de pagamento?

5) O consumidor comprou outros produtos que não sejam de telefonia? Quais? NÃO

5.1)Quais?

6) O motivo principal da visita à banca era a compra do chip pré-pago?

7) $O$ consumidor apresentou indícios de que conhece o varejista? (Chamou pelo nome, falou de situações passadas, tratamento próximo ou informal)

7.1) Qual?

1) Observei que você adquiriu um chip pré-pago. Com que frequência você costuma trocar de chip (MESES)?

2) Por que você optou por comprar o chip em uma banca de jornal?

3) O que fez com que você escolhesse essa banca de jornal especificamente?

4) Antes de entrar na banca, você já sabia que aqui vendia chip? Se sim, como sabia?

5) Você costuma comprar outros produtos nesta banca?

6) Você conhece o jornaleiro pelo nome? Fale sobre sua relação com o jornaleiro desta banca ou de outra onde você costuma comprar.

7) Quais são os fatores que levam você a comprar um produto em uma banca de jornal ao invés de comprar em outros locais que tenham o mesmo produto?

8) $O$ que levou você a escolher a operadora $X$ ?

9) Você já havia decidido que queria o chip desta operadora ou procurou maiores informações com o jornaleiro?

10) Antes de realizar a compra do chip, você lembra de ter visto algum materia de comunicação falando sobre o produto que você comprou?

11) Fale sobre de que forma $o$ atendimento do jornaleiro interferiu na sua

compra.

12) Fale também sobre as formas de pagamento na banca de jornal. Qual é a forma de pagamento que você prefere utilizar para comprar um chip?

13) A forma de pagamento é um fator que te levou a comprar na banca de jornal?
$01 / 02 / 2018$

Banca da praça

Madureira

Isabel costa

ATENDENTE

Casado

MADUREIRA

SIM

PEDE DIRETAMENTE

TIM

$\operatorname{SIM}$

RECARGA

SIM

DINHEIRO

NÃO

NENHUM

$\operatorname{sIM}$

TRATAMENTO INFORMAL APARENTE CONSUMIDOR FREQUENTE.

PROXIMIDADE

LOCAL DE PASSAGEM

PROXIMIDADE

LOCAL DE PASSAGEM

TODAS AS BANCAS VENDEM CHIP E RECARGA, NESSA EU COSTUMO FAZER RECARGA DE CELULAR.

NÃO MUITO, QUANDO EU FUMAVA ERA BOM QUE ELE SEMPRE TINHA CIGARRO.

NÃO SEI O NOME DELE NÃO. MAS SEI QUE ELE É BEM GENTE FINA E TRABALHA AQUI NA PRAÇA A UNS 10 ANOS.

AH.... É RAPIDINHO, EU SO NÃO GOSTO DE FILA. POR QUE ALGUNS LUGARES VOCE DEMORA MUITO PARA SER ATENDIDO.

ELA TEM O ZAP DIRETO SEM CUSTO. FICA MUITO MAIS BARATO PRA QUEM USA MUITA INTERNET.

JÁ ERA TIM ANTES, VOU MANTER COM ELA.

SIM UM PORTA CHIP COM PROPAGANDA PERTO DO BALCAO.

AH, ELE É BEM ATENCIOSO E EU JÁ ESTOU ACOSTUMADA A COMPRAR COM ELE A MUITO TEMPO. TEM UM BOM ATENDIMENTO, TODO MUNDO CONHECE A BANCA AQUI NA PRAÇA. EU COMPRO NO DINHEIRO MESMO, ELE AQUI NÃO ACEITA CARTÃO. EU PREFIRO DINHEIRO QUE É MAIS RAPIDO E TAMBEM NÃO DA PRA PAGAR DE OUTRA FORMA NÉ.

NÃO FAZ DIFERENÇA ISSO PRA MIM NÃO. COMPREI AQUI PORQUE É PERTINHO MESMO E MAIS RAPIDO. 


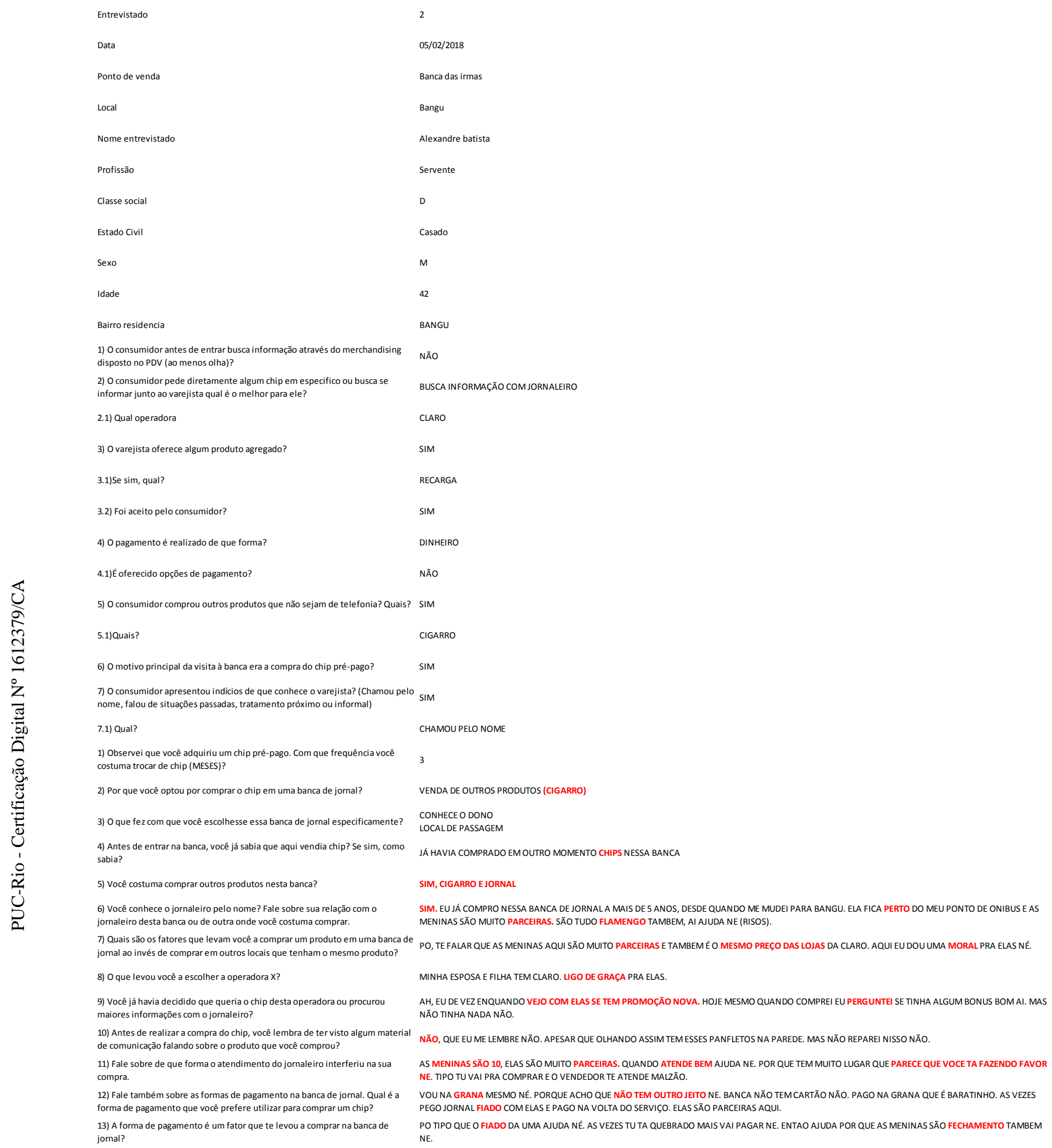




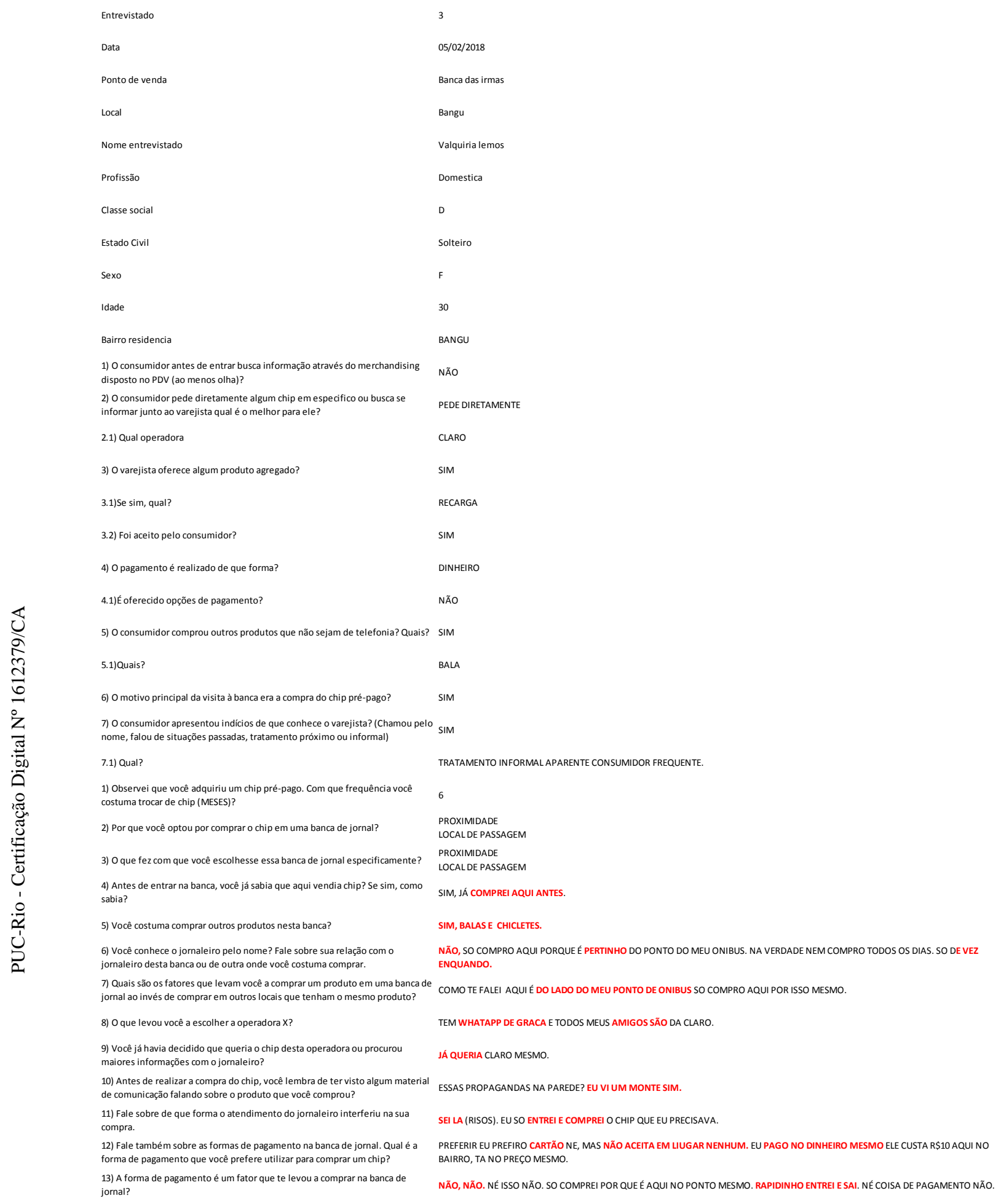




\section{Entrevistado}

Data

Ponto de venda

local

Nome entrevistado

Profissão

Classe social

Estado Civil

Sexo

Idade

Bairro residencia

1) O consumidor antes de entrar busca informação através do merchandising disposto no PDV (ao menos olha)

2) $O$ consumidor pede diretamente algum chip em especifico ou busca se informar junto ao varejista qual é o melhor para ele?

2.1) Qual operadora

3) 0 varejista oferece algum produto agregado?

3.1)Se sim, qual?

3.2) Foi aceito pelo consumidor?

4) O pagamento é realizado de que forma?

4.1)É oferecido opcões de pagamento?

5) O consumidor comprou outros produtos que não sejam de telefonia? Quais? SIM

5.1)Quais?

6) O motivo principal da visita à banca era a compra do chip pré-pago?

apresentou indícios de que conhece o varejista? (Chamou pelo $N$ ÃO

7.1) Qual?

1) Observei que você adquiriu um chip pré-pago. Com que frequência você costuma trocar de chip (MESES)?

2) Por que você optou por comprar o chip em uma banca de jornal?

3) O que fez com que você escolhesse essa banca de jornal especificamente?

de entrar na banca, você já sabia que aqui vendia chip? Se sim, como sabia?

5) Você costuma comprar outros produtos nesta banca?

6) Você conhece o jornaleiro pelo nome? Fale sobre sua relação com o jornaleiro desta banca ou de outra onde você costuma comprar.

7) Quais são os fatores que levam você a comprar um produto em uma banca jornal ao invés de comprar em outros locais que tenham o mesmo produto?

8) $O$ que levou você a escolher a operadora $X$ ?

9) Você já havia decidido que queria o chip desta operadora ou procurou maiores informas̄es com o jornaleiro?

10) Antes de realizar a compra do chip, você lembra de ter visto algum mate de comunicação falando sobre o produto que você comprou?

11) Fale sobre de que forma o atendimento do jornaleiro interferiu na sua compra.

12) Fale também sobre as formas de pagamento na banca de jornal. Qual é a

forma de pagamento que você prefere utilizar para comprar um chip?

13) A forma de pagamento é um fator que te levou a comprar na banca de jornal?

N/A

N/A

N/A
06/02/2018

Banca dona vera

Taquara

Bruno fernandes

Pedreiro

Solteiro

TAQUARA

SIM

BUSCA INFORMAÇ̃̃O COM JORNALERRO

CLARO

NÃO

DINHEIRO

NÃO

JORNAL

PROXIMIDADE

LOCALDE PASSAGEM

SINALZZAÇÃO DE VENDA DE CHIP

NÃO, EUVI NO CARTAZ QUE FICA AQUI FORA.

NÃO, PRIMEIRA VEZ QUE VENHO NELA.

CONHEÇO NÃO MOÇO. MAS É BEM ANTIGO AI, EUJÁ MORO AQUI A UNS 15 ANOS E ELE JÁ TAVA AI EUACHO.

AQUI NORMALMENTE TEM TUDO NE. O MEIA HORA (JORNAL) QUE EU VEJO DEPOIS DO JOGO E CHIP TAMBEM NE. TIPO EU SO NÃO VEJO MUITAS BANCAS VENDENDO BEBIDAS MAS TEM EM MUITAS TAMBEM.

OS AMIGOS E FAMILIA SÃo TUDO CLARO. AI NÃO DA NÉ. TEM PROMOÇão PRA FALAR.

PERGUNTEI SE TINHA O CHIP DA CLARO QUE JÁ VEM COM CREDITO DE RS10. ELE TEM BONUS E TU FICA TIPO 1 SEMANA DIRETO SEM ACABAR OS CREDITOS. AI SEMPRE COMPRO ESSE MESMO. MAS NÃO SABIA SE TINHA ESSE.

TINHA UM CARTAZ GRANDÃo FALANDO O PREÇO DO CHIP AQUI NA PORTA DELE.

PO A DONA ME ATENDEU BEM E ME FALOU QUE TINHA AQUELE CHIP COM RŚ10 QUE TE FALEI. SIMPATICA A MOÇA, ME TRATOU BENZÃo.

DINHEIRO

NÃo, NÃoÉNÃo 


\begin{tabular}{|c|c|}
\hline Entrevistado & 5 \\
\hline Data & $07 / 02 / 2018$ \\
\hline Ponto de venda & Banca do didiu \\
\hline Local & Campogrande \\
\hline Nome entrevistado & Rafael simões \\
\hline Profissão & Vendedor \\
\hline Classe social & c \\
\hline Estado Civil & Solteiro \\
\hline Sexo & M \\
\hline Idade & 28 \\
\hline Bairro residencia & PACIENCIA \\
\hline $\begin{array}{l}\text { 1) O consumidor antes de entrar busca informação através do merchandising } \\
\text { disposto no PDV (ao menos olha)? }\end{array}$ & NÃO \\
\hline $\begin{array}{l}\text { 2) O consumidor pede diretamente algum chip em especifico ou busca se } \\
\text { informar junto ao varejista qual é o melhor para ele? }\end{array}$ & PEDE DIRETAMENTE \\
\hline 2.1) Qual operadora & vivo \\
\hline 3) O varejista oferece algum produto agregado? & SIM \\
\hline 3.1)Se sim, qual? & RECARGA \\
\hline 3.2) Foi aceito pelo consumidor? & $\operatorname{siM}$ \\
\hline 4) O pagamento é realizado de que forma? & DINHEIRO \\
\hline 4.1)É oferecido opções de pagamento? & NÃO \\
\hline 5) O consumidor comprou outros produtos que não sejam de telefonia? Quais? & NÃO \\
\hline 5.1)Quais? & NENHUM \\
\hline 6) O motivo principal da visita à banca era a compra do chip pré-pago? & SIM \\
\hline $\begin{array}{l}\text { 7) O consumidor apresentou indícios de que conhece o varejista? (Chamou pelo } \\
\text { nome, falou de situações passadas, tratamento próximo ou informal) }\end{array}$ & SIM \\
\hline 7.1) Qual? & TRATAMENTO INFORMAL APARENTE CONSUMIDOR FREQUENTE. \\
\hline $\begin{array}{l}\text { 1) Observei que você adquiriu um chip pré-pago. Com que frequência você } \\
\text { costuma trocar de chip (MESES)? }\end{array}$ & 3 \\
\hline 2) Por que você optou por comprar o chip em uma banca de jornal? & COMPRO SEMPRE AQUI. EU TROCO DE CHIP DIRETO PARA PODER MANTER CONTATO COM OS CLIENTES AI SEMPRE PEGO AQUI. \\
\hline 3) O que fez com que você escolhesse essa banca de jornal especificamente? & COMPRO SEMPRE AQUI. EU TROCO DE CHIP DIRETO PARA PODER MANTER CONTATO COM OS CLIENTES AI SEMPRE PEGO AQUI. \\
\hline $\begin{array}{l}\text { 4) Antes de entrar na banca, você já sabia que aqui vendia chip? Se sim, como } \\
\text { sabia? }\end{array}$ & SIM, COMO TE FALEI EU JÁ SOU CLIENTE DAQUI. \\
\hline 5) Você costuma comprar outros produtos nesta banca? & SIM, JORNAL NOIRMALMENTE. \\
\hline $\begin{array}{l}\text { 6) Você conhece o jornaleiro pelo nome? Fale sobre sua relação com o } \\
\text { jornaleiro desta banca ou de outra onde você costuma comprar. }\end{array}$ & SIM, DIDIU É DAS ANTIGAS AQUI NO CALÇADÃO. MUITO PARCEIRO TEM NOME NA AREA AQUI. \\
\hline $\begin{array}{l}\text { 7) Quais são os fatores que levam você a comprar um produto em uma banca de } \\
\text { jornal ao invés de comprar em outros locais que tenham o mesmo produto? }\end{array}$ & $\begin{array}{l}\text { CARA, EU COMPRO NO DIDIU PORQUE SEI QUE TEM AS COISAS QUE PRECISO. MAS NÃO COSTUMO COMPRAR MUITO JORNAL ENTÃO } \\
\text { NÃO CONHECO VARIAS BANCAS. }\end{array}$ \\
\hline 8) O que levou você a escolher a operadora $X$ ? & $\begin{array}{l}\text { PEGA LA EM CASA E MUITO BEM EM CAMPO GRANDE. IMPORTANTE POR QUE EU ATENDO AS MINHAS VENDAS POR TELEFONE. AI } \\
\text { SABE NE, FAZ A DIFERENÇA ISSO. }\end{array}$ \\
\hline $\begin{array}{l}\text { 9) Você já havia decidido que queria o chip desta operadora ou procurou } \\
\text { maiores informaçôes com o jornaleiro? }\end{array}$ & $\begin{array}{l}\text { SÓ USO DA VIVO. JÁ ERA ESSE MESMO, IA PEGAR OUTRO NÃO. CLARO EU JÁ TIVE E ROUBAVA DE MAIS OS CREDITOS TAMBEM, TEM } \\
\text { QUE SER VIVO MESMO. }\end{array}$ \\
\hline $\begin{array}{l}\text { 10) Antes de realizar a compra do chip, você lembra de ter visto algum material } \\
\text { de comunicação falando sobre o produto que você comprou? }\end{array}$ & NÃO, ACHO QUE TINHA NADA DISSO NÃO. \\
\hline $\begin{array}{l}\text { 11) Fale sobre de que forma o atendimento do jornaleiro interferiu na sua } \\
\text { compra. }\end{array}$ & $\begin{array}{l}\text { PO DIDIU É FECHAMENTO DAQUI DA AREA PO. JÁ ATENDO AQUI NA AREA DE CAMPO GRANDE A MUITO TEMPO E DIDIU JÁ TRABALHA } \\
\text { A ANOS AQUI. SUPER CONSIDERADO AQUI NA AREA. }\end{array}$ \\
\hline $\begin{array}{l}\text { 12) Fale também sobre as formas de pagamento na banca de jornal. Qual é a } \\
\text { forma de pagamento que você prefere utilizar para comprar um chip? }\end{array}$ & ELES NÃO ACEITAM CARTÃO NÃO. SE ACEITASSE ATE PAGAVA MAS É SO DINHEIRO. \\
\hline $\begin{array}{l}\text { 13) A forma de pagamento é um fator que te levou a comprar na banca de } \\
\text { jornal? }\end{array}$ & NÃO \\
\hline
\end{tabular}




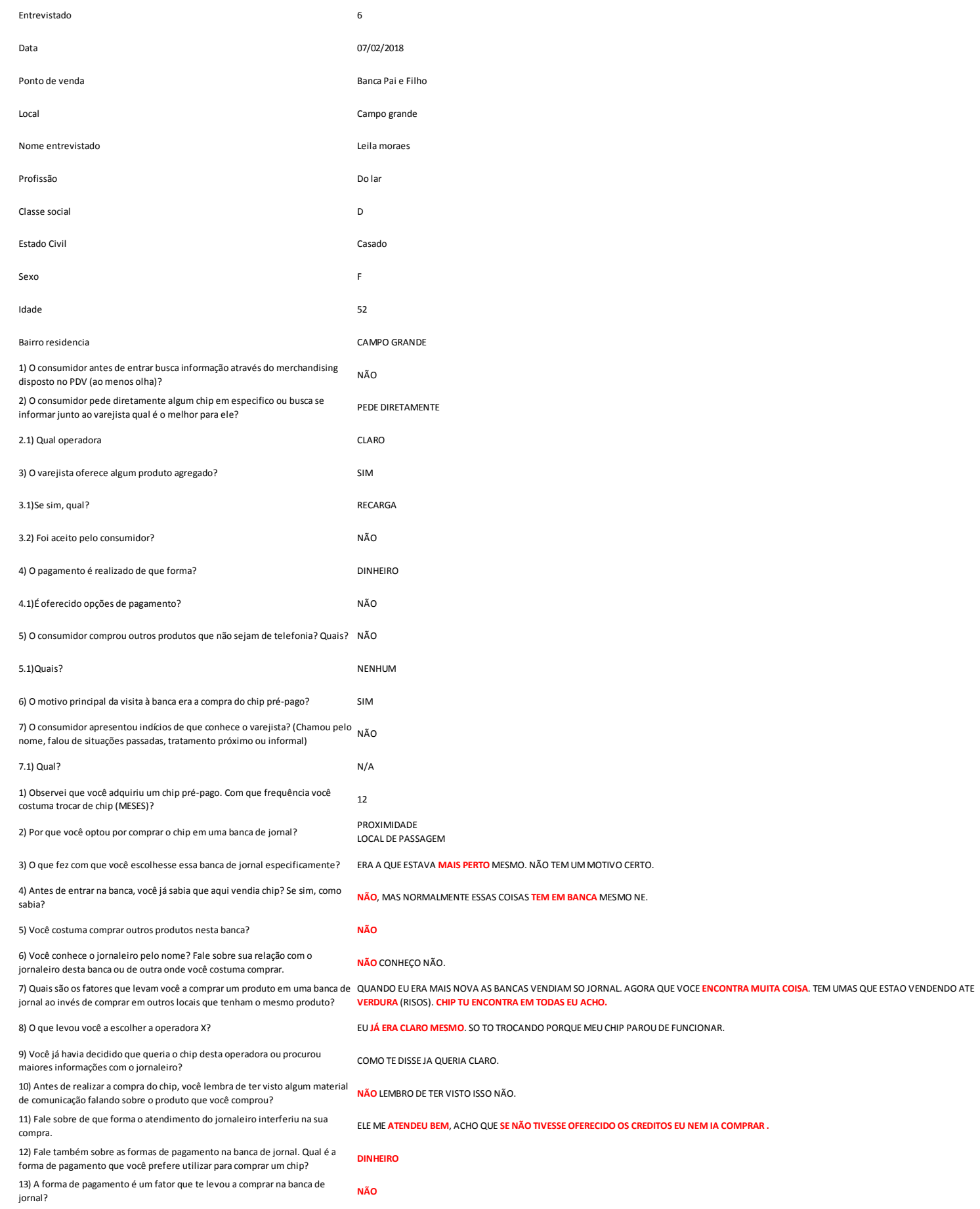




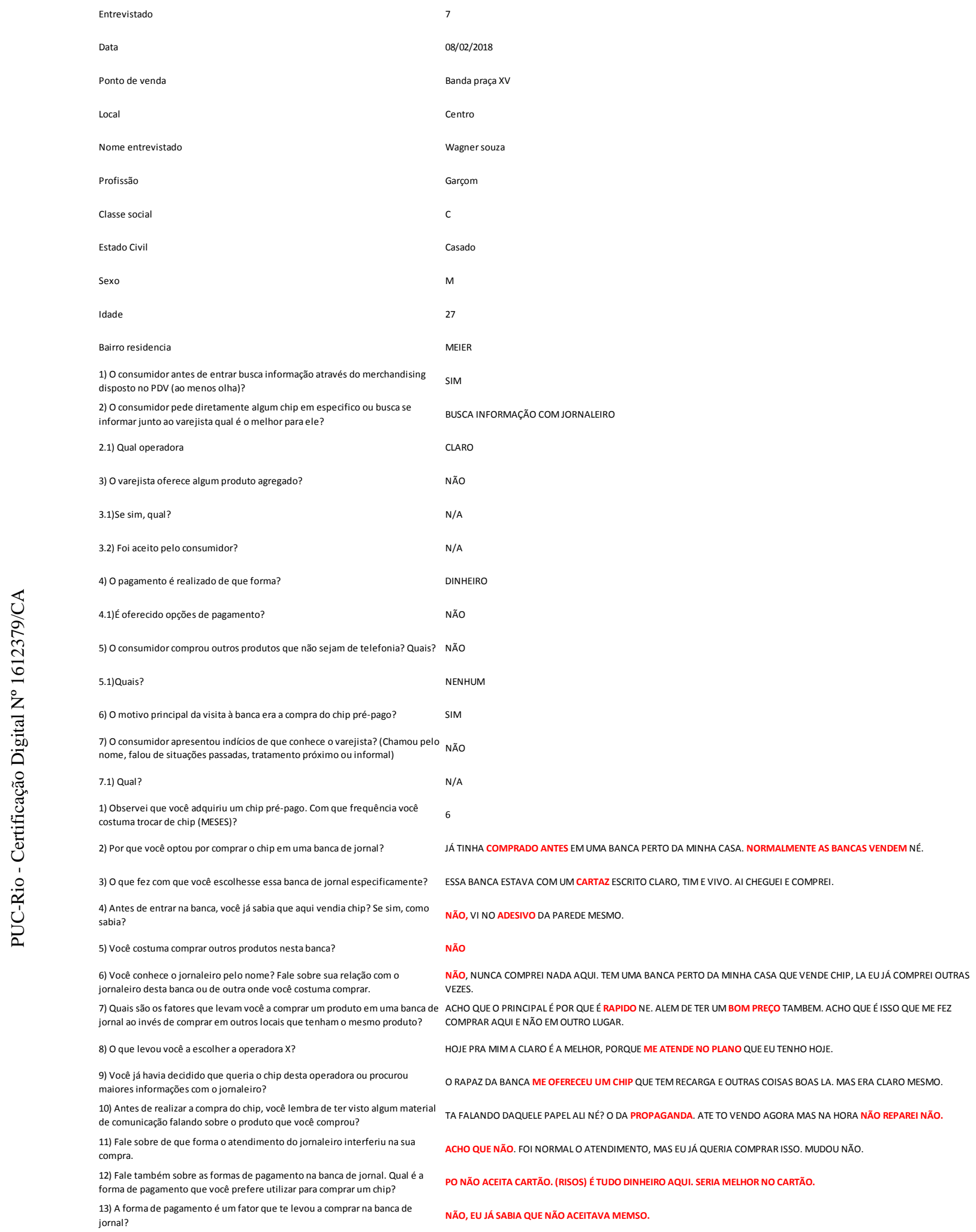




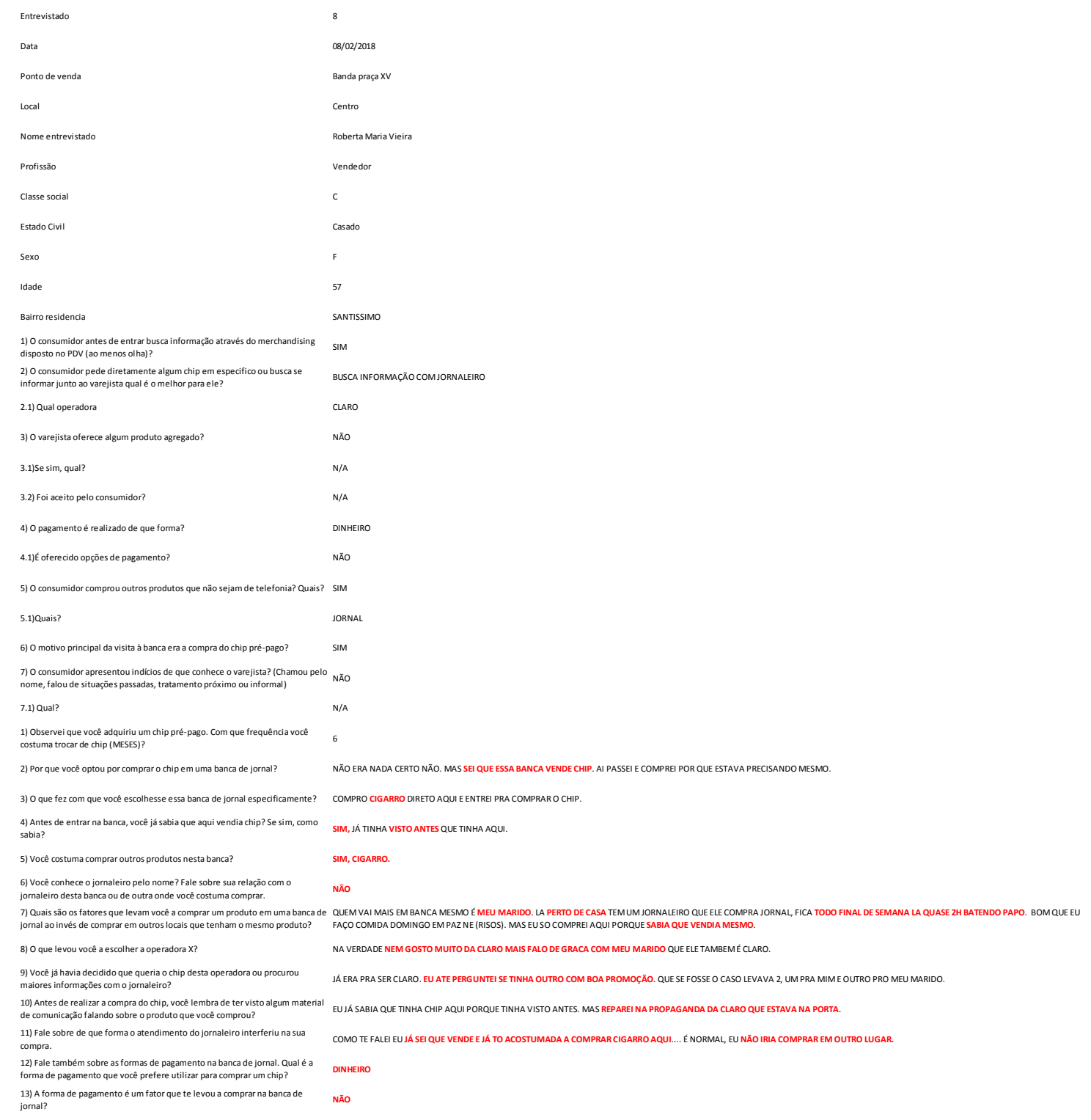




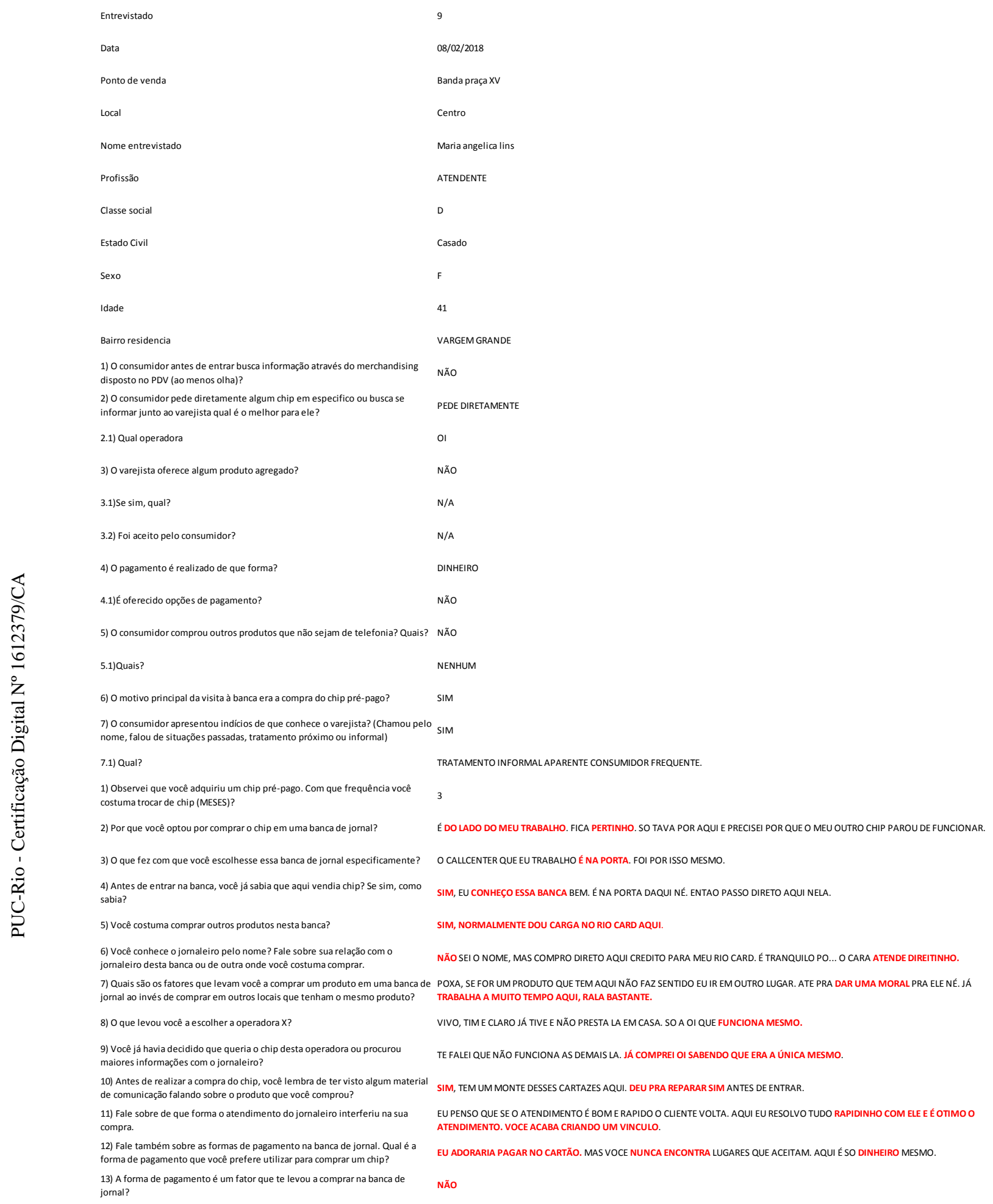


Entrevistado

Data

Ponto de venda

Local

Nome entrevistado

Profissão

Classe social

Estado Civil

Sexo

Idade

Bairro residencia

1) $O$ consumidor antes de entrar busca informação através do merchandising disposto no PDV (ao menos olha)?

2) $O$ consumidor pede diretamente algum chip em especifico ou busca se informar junto ao varejista qual é o melhor para ele?

2.1) Qual operadora

3) $O$ varejista oferece algum produto agregado?

3.1)Se sim, qual?

3.2) Foi aceito pelo consumidor?

4) O pagamento é realizado de que forma?

4.1)É oferecido opç̃es de pagamento?

5) O consumidor comprou outros produtos que não sejam de telefonia? Quais? NÃO

5.1)Quais?

6) O motivo principal da visita à banca era a compra do chip pré-pago?

7) $O$ consumidor apresentou indicios de que conhece ovarejista? (Chamoupelo nome, falou de situaç̃ões passadas, tratamento próximo ou informal)

7.1) Qual?

1) Observei que você adquiriu um chip pré-pago. Com que frequência você costuma trocar de chip (MESES)?

2) Por que você optou por comprar o chip em uma banca de jornal?

3) O que fez com que você escolhesse essa banca de jornal especificamente?

4) Antes de entrar na banca, você já sabia que aqui vendia chip? Se sim, como sabia?

5) Você costuma comprar outros produtos nesta banca?

6) Você conhece o jornaleiro pelo nome? Fale sobre sua relação com o

jornaleiro desta banca ou de outra onde você costuma comprar.

7) Quais são os fatores que levam você a comprar um produto em uma banca de jornal ao invés de comprar em outros locais que tenham o mesmo produto?

8) $O$ que levou você a escolher a operadora $X$

9) Você já havia decidido que queria o chip desta operadora ou procurou maiores informações com o jornaleiro?

10) Antes de realizar a compra do chip, você lembra de ter visto algum material de comunicação falando sobre o produto que você comprou?

11) Fale sobre de que forma o atendimento do jornaleiro interferiu na sua

compra.

12) Fale também sobre as formas de pagamento na banca de jornal. Qual é a forma de pagamento que você prefere utilizar para comprar um chip?

13) A forma de pagamento é um fator que te levou a comprar na banca de jornal?

TIM

$\operatorname{SIM}$

SIM

SIM

NÃO

\section{$21 / 02 / 2018$}

Banca Pai e Filho

Campo grande

Bruna lopes ferreira

Domestica

Casado

GUARATIBA

NÃO

PEDE DIRETAMENTE

RECARGA

DINHEIRO

NÃo

NENHUM

Na

VIM NO CALÇADÃO PRA PEGAR MEU DOCUMENTO E PEGUEI UM CHIP NOVO PRA PODER APROVEITAR A PROMOÇÃO QUE TA NA TV DA TIM.

ELA TAVA AQUI JÁ PERTO DE ONDE EU ESTAVA. TINHA O CARTAZ DA TIM TAMBEM COM A PROPAGANDA QUE TE FALEI.

SIM, TAVA NO FOLHETINHO ALL QUE TE MOSTREI.

NÃo

CHIP SÓ TEM NESSES LUGARES NÉ. ENTÃo É MEIO QUE POR ISSO QUE EU COMPREI AQUI. A TIM TA COM UMA PROMOÇãO DE INTERNET E WHATAPP QUE TA PASSANDO NA TV. O MEU OUTRO CHIP TA BLOQUEADO, MAS ERA CLARO. AI AGORA RESOLVI TESTAR A TIM DESSA VEZ.

ENCONTREI A PROMOÇãO NA TV E ACABEI VENDO AQUI PRA VENDER.

SIMAQUELE FOLHETINHO QUE TE FALEI. TEMUMBEMAQUI NA FRENTE DA BANCA.

NÃO, VOU TE FALAR. ACHO QUE NÃO ALTERA NADA NÃO (RISOS)

ESSAS COISAS EU SO COMPRO EM DINHEIRO MESMO. BARATINHO NE...

NÃO 


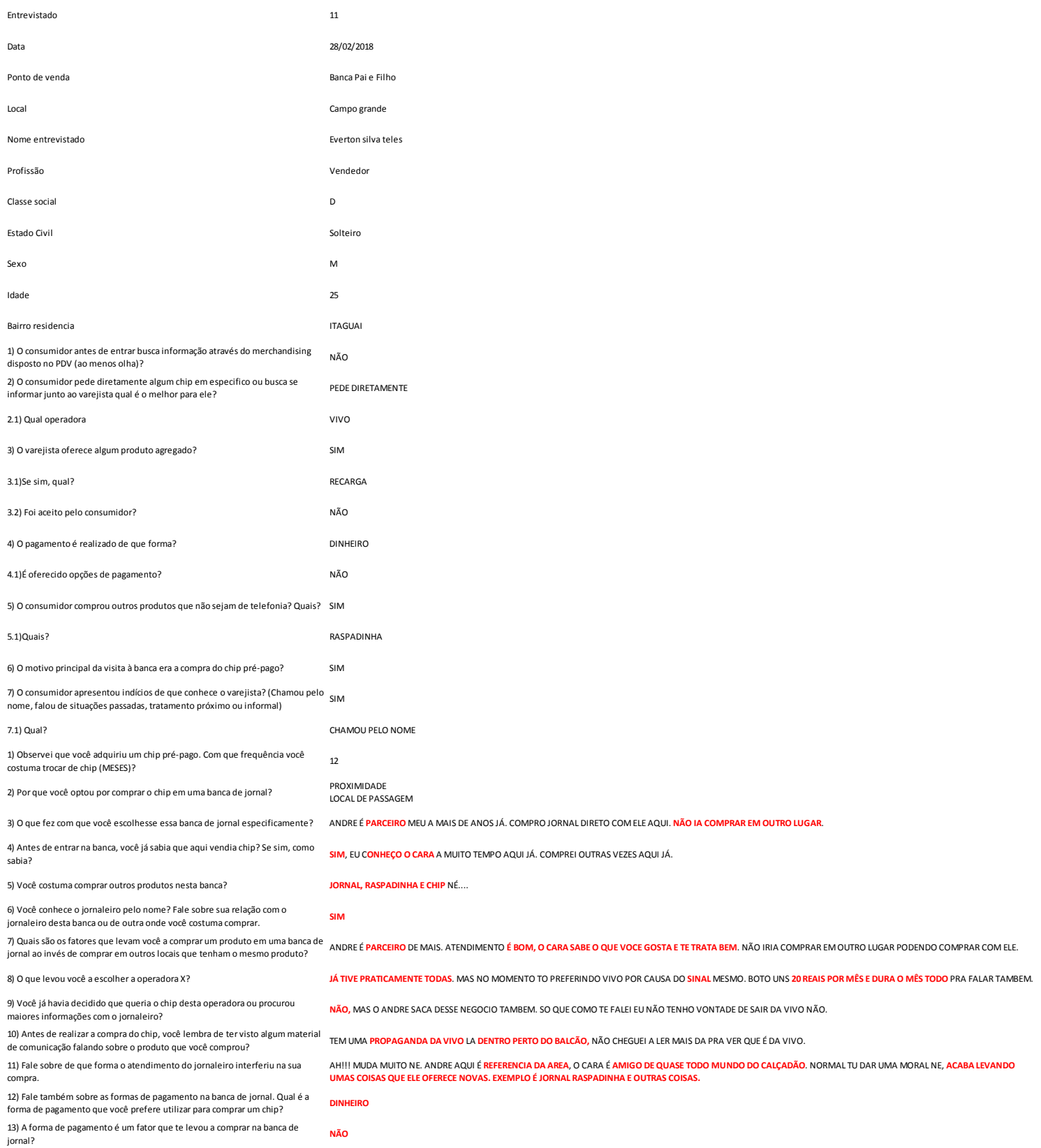

